\title{
Electroluminescence from HgTe Nanocrystals and its Use for Active Imaging
}

Junling Qu ${ }^{1}$, Prachi Rastogi ${ }^{1}$, Charlie Gréboval ${ }^{1}$, Delphine Lagarde ${ }^{2}$, Audrey Chu ${ }^{1}$, Corentin Dabard $^{1}$, Adrien Khalili' ${ }^{1}$, Hervé Cruguel ${ }^{1}$, Cédric Robert ${ }^{2}$, Xiang Zhen $\mathrm{Xu}^{3}$, Sandrine Ithurria ${ }^{3}$, Mathieu G. Silly ${ }^{4}$, Simon Ferré5 ${ }^{5}$ Xavier Marie ${ }^{2}$, Emmanuel Lhuillier ${ }^{1^{*}}$

${ }^{1}$ Sorbonne Université, CNRS, Institut des NanoSciences de Paris, INSP, F-75005 Paris, France. ${ }^{2}$ Université de Toulouse, INSA-CNRS-UPS, LPCNO, Toulouse, France.

${ }^{3}$ Laboratoire de Physique et d'Etude des Matériaux, ESPCI-Paris, PSL Research University, Sorbonne Université Univ Paris 06, CNRS UMR 8213, 10 rue Vauquelin 75005 Paris, France. ${ }^{4}$ Synchrotron-SOLEIL, Saint-Aubin, BP48, F91192 Gif sur Yvette Cedex, France.

${ }^{5}$ New Imaging Technologies SA, 1 impasse de la Noisette 91370 Verrières le Buisson, France.

To whom correspondence should be sent: el@insp.upmc.fr

\section{Table of content}

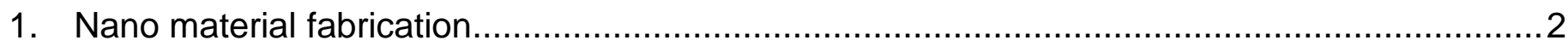

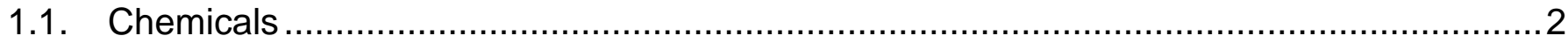

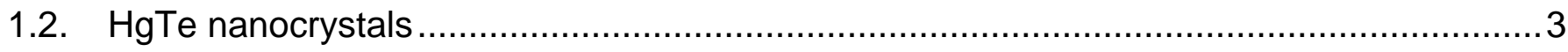

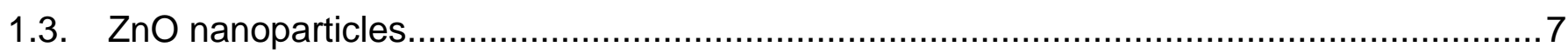

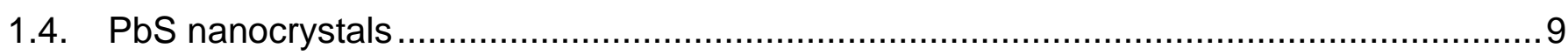

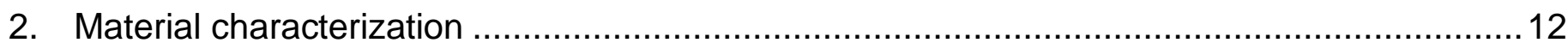

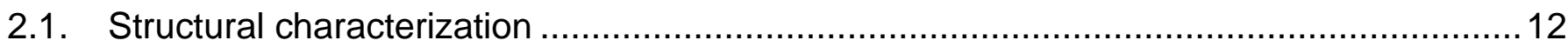

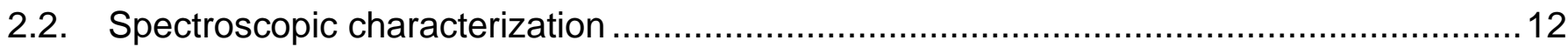

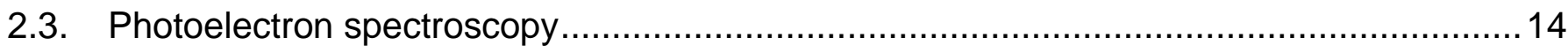

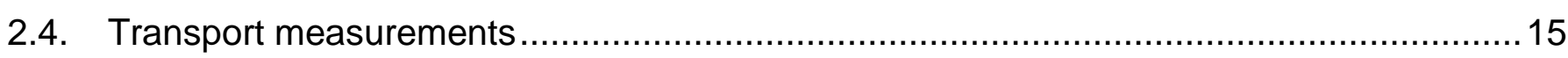

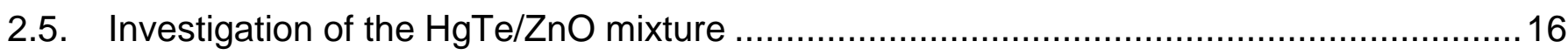

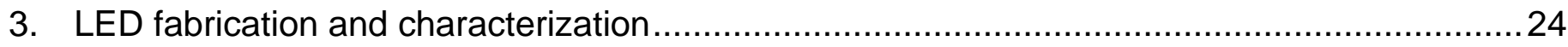

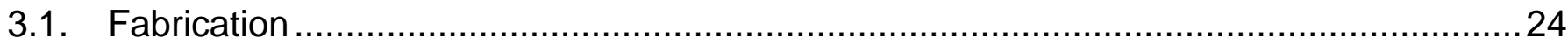

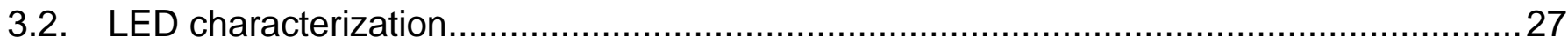

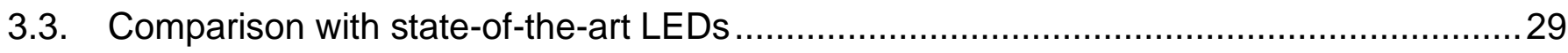

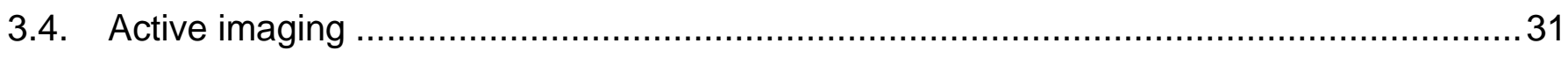

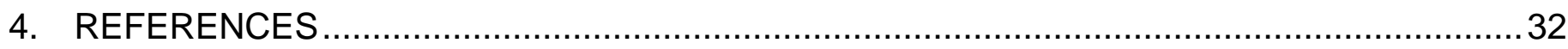




\section{Nano material fabrication}

\subsection{Chemicals}

Mercury chloride $\left(\mathrm{HgCl}_{2}\right.$, Strem Chemicals, 99\%), Tellurium powder (Te, Sigma-Aldrich, 99.99\%), Octadecene (ODE, Acros Organics, 90\%), Lead oxide (PbO, Strem Chemicals, 99.999+\%-), Zinc acetate dihydrate $\left(\mathrm{Zn}\left(\mathrm{CH}_{3} \mathrm{COO}\right)_{2}\right.$, Sigma, 99.999\%), Oleic acid (OA, Alfa Aesar 90\%), Hexamethyldisilathiane $\left(\mathrm{TMS}_{2} \mathrm{~S}\right.$, Sigma Aldrich, synthesis grade), Hydrochloric acid $(\mathrm{HCl}$, Mieuxa, 25\%), Potassium Hydroxide ( $\mathrm{KOH}$, Sigma 90\%), Ammonium iodine $\left(\mathrm{NH}_{4} \mathrm{l}\right.$, Alfa Aesar, $\left.\geq 99 \%\right), 1,2$ Ethanedithiol (EDT, Fluka, 98\%), trioctylphosphine (TOP, Cytek, 90\%), Oleylamine (OLA, Acros, 80-90\%), Dodecanethiol (DDT, Sigma-Aldrich, 98\%), Chloroform (Carlo Erba), Ethanol absolute anhydrous (Carlo Erba, 99.9\%), Methanol (Carlo Erba, 99.8\%), Toluene (Carlo Erba, 99.3\%), nOctane (SDS, 99\%), n-Heptane (Merck, >99\%), n-Hexane (VWR, 99\%), N,N-Dimethylformamide (DMF, Sigma Aldrich), Butylamine (Alpha 99\%).

All chemicals are used as received, except oleylamine which is centrifuged before use.

Mercury and lead compounds are highly toxic. Handle them with special care. 


\subsection{HgTe nanocrystals}

$1 \mathrm{M}$ TOP:Te precursor: $2.54 \mathrm{~g}$ of Te powder was mixed in $20 \mathrm{~mL}$ of TOP in a three-neck flask. The flask was kept under vacuum at room temperature for $5 \mathrm{~min}$ and then the temperature was raised to $100^{\circ} \mathrm{C}$. Furthermore, degassing of flask was conducted for the next $20 \mathrm{~min}$. The atmosphere was switched to $\mathrm{Ar}$ and the temperature was raised to $275^{\circ} \mathrm{C}$. The solution was stirred until a clear orange coloration was obtained. The flask was cooled down to room temperature and the color switches to yellow. Finally, this solution was transferred to a nitrogen-filled glove box for storage.

HgTe nanocrystal synthesis : The synthesis is taken from Geiregat et al. ${ }^{1}$ In a $25 \mathrm{~mL}$ three-neck flask, $270 \mathrm{mg}$ of $\mathrm{HgCl}_{2}(1 \mathrm{mmol}), 1.6 \mathrm{~mL}(6 \mathrm{mmol})$ of dodecanethiol and $8 \mathrm{~mL}$ of oleylamine are degassed under vacuum at $110^{\circ} \mathrm{C}$ for $1 \mathrm{~h}$. The atmosphere is switched to $\mathrm{N}_{2}$ and the temperature is set to $60^{\circ} \mathrm{C}$. When the temperature stabilizes at $60^{\circ} \mathrm{C}, 1 \mathrm{~mL}$ of TOP:Te solution (1 M) is quickly injected, and the growth is allowed for $1 \mathrm{~min}$. The reaction is quenched by injecting $10 \mathrm{~mL}$ of toluene. A water batch is used to further cool down the mixture. The reaction mixture is precipitated by methanol and redispersed in toluene twice. Then a centrifugation is conducted while the mixture is dispersed in $7.5 \mathrm{~mL}$ of toluene to remove the colloidally unstable parts. The nanocrystals are precipitated and redispersed with methanol/toluene for another three to four times and finally stored at a concentration of $30 \mathrm{mg} \cdot \mathrm{mL}^{-1}$ in toluene. The solution is filtered with a $0.22 \mu \mathrm{m}$ PTFE filter before use. The obtained nanocrystals have a zinc blende structure according to $\mathrm{X}$-ray diffraction, see Figure $\mathrm{S} 1$.

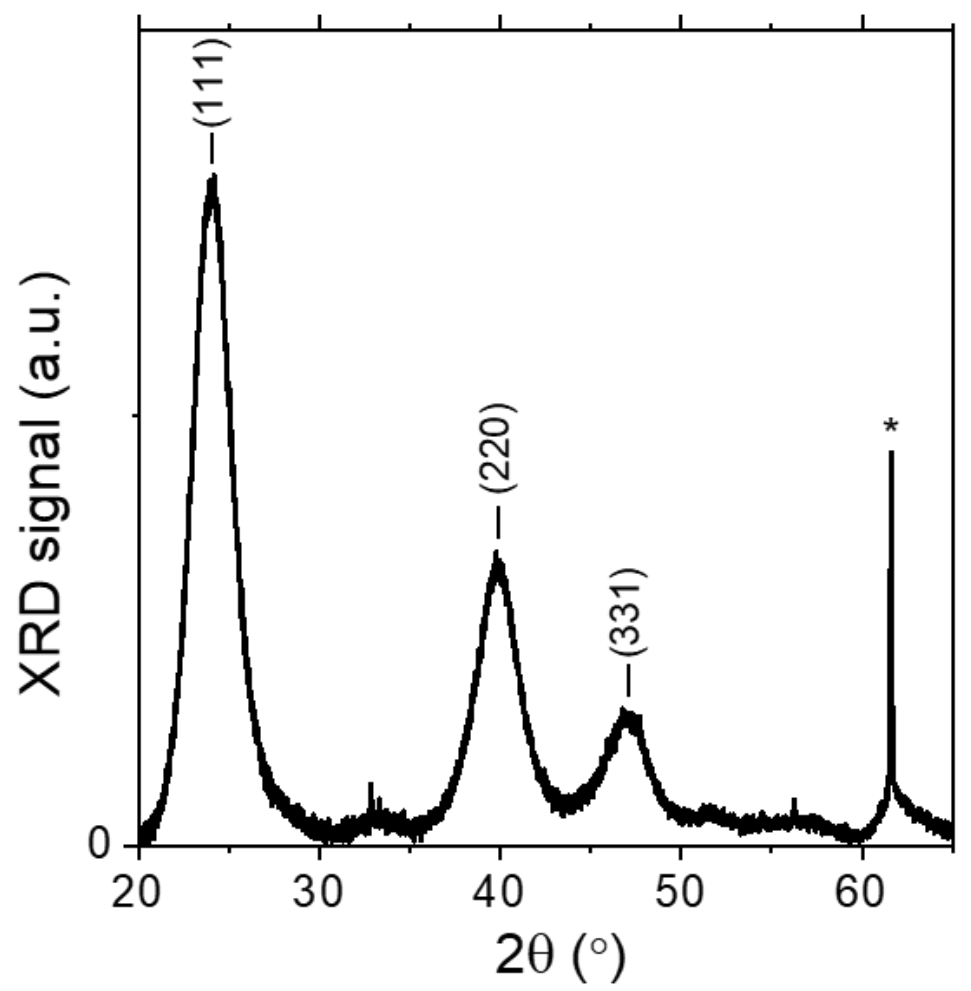

Figure $S 1$ XRD diagram of HgTe NCs. The peak * comes from the substrate.

We have also analyzed the temperature dependence of the HgTe band gap through the change of the photoluminescence $(\mathrm{PL})$ spectrum as a function of temperature. Two clear trends can be observed: (i) the higher the temperature, the bluer the PL signal (Figure $S 2 b$ ). This inverted 
temperature dependency compared to conventional semiconductors is the result of $\mathrm{HgTe}$ specific band structure. ${ }^{2}$ We determine a value of $68 \mu \mathrm{eV} . \mathrm{K}^{-1}$ for $\mathrm{dEG} / \mathrm{dT}$. The second trend relates to an increase of the PL signal while the temperature is reduced (Figure $S 2 a$ ).
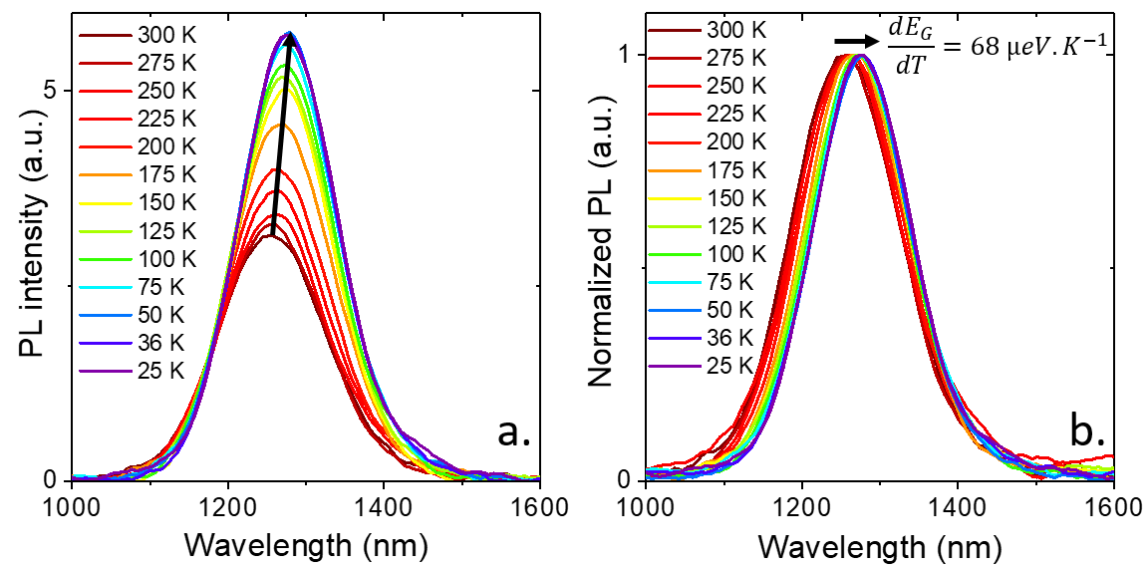

Figure S $2 \mathrm{HgTe} C Q D$ PL intensity (a.) and normalized PL (b.) spectra for different temperatures.

To finish with $\mathrm{HgTe}$, we probe its photoconductive properties. Once the material is processed under thin film form, with ligand exchange to make it conductive, we observe a clear photoconduction signature, see Figure $S 3 b$ and $c$. The photocurrent spectrum follows quite well the absorption feature with a small red shift which is typical of the ligand exchange procedure, see Figure $S 3 a$.
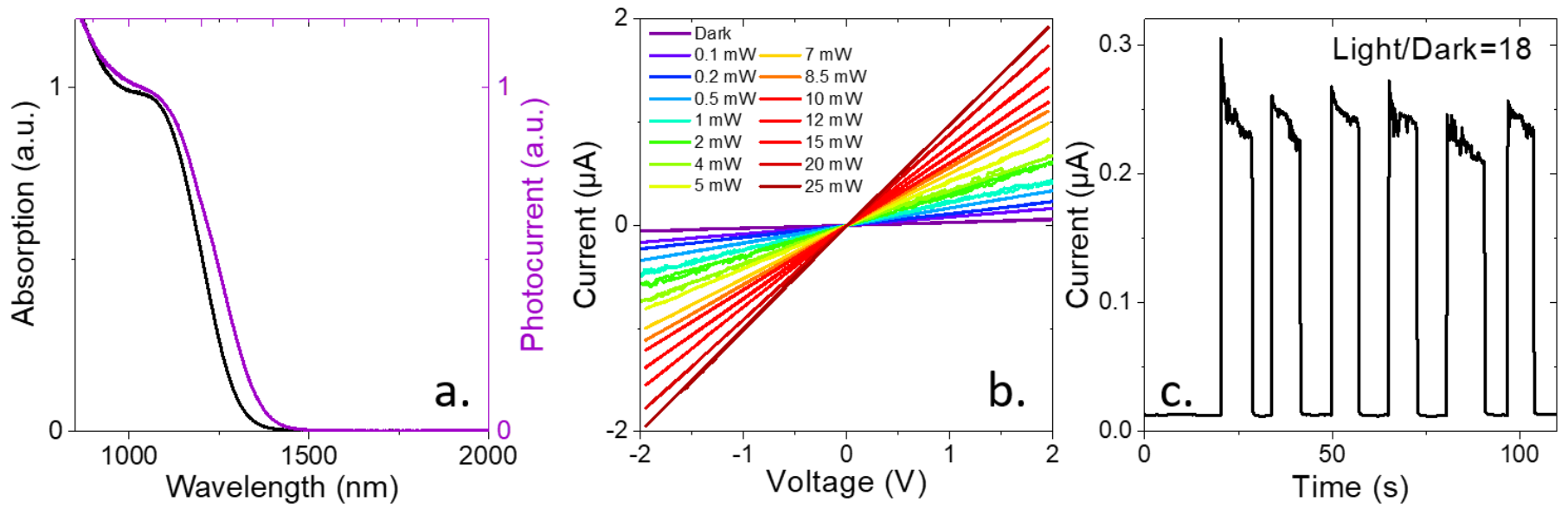

Figure S 3 a. Absorption and photocurrent spectra for a HgTe CQD-based thin film. b. Dark current and photocurrent for different illumination powers of a film of HgTe capped with MPA. The incident light wavelength is $940 \mathrm{~nm}$. c. Current as a function of time while pulses of light are shone onto the $\mathrm{HgTe}$ film. The illumination wavelength is $940 \mathrm{~nm}$ and the incident power is $4 \mathrm{~mW}$. The bias is set at $0.5 \mathrm{~V}$.

From photoemission, we determine the work function of the HgTe to be $4.52 \mathrm{eV}$ (Figure S 4a), consistent with the previously value reported for $\mathrm{HgTe} C Q D s$. $^{3,4} \mathrm{The}_{\mathrm{b}}-\mathrm{E}_{\mathrm{F}}$ value is estimated to be $\approx 0.24 \mathrm{eV}$ (Figure $S 4 \mathrm{~b}$ ), this suggests a Fermi level in the bottom half of the band gap (Figure $S 4 \mathrm{c}$ ) and a $p$-nature for this material which is the common behavior for small size HgTe. ${ }^{5,6}$ 

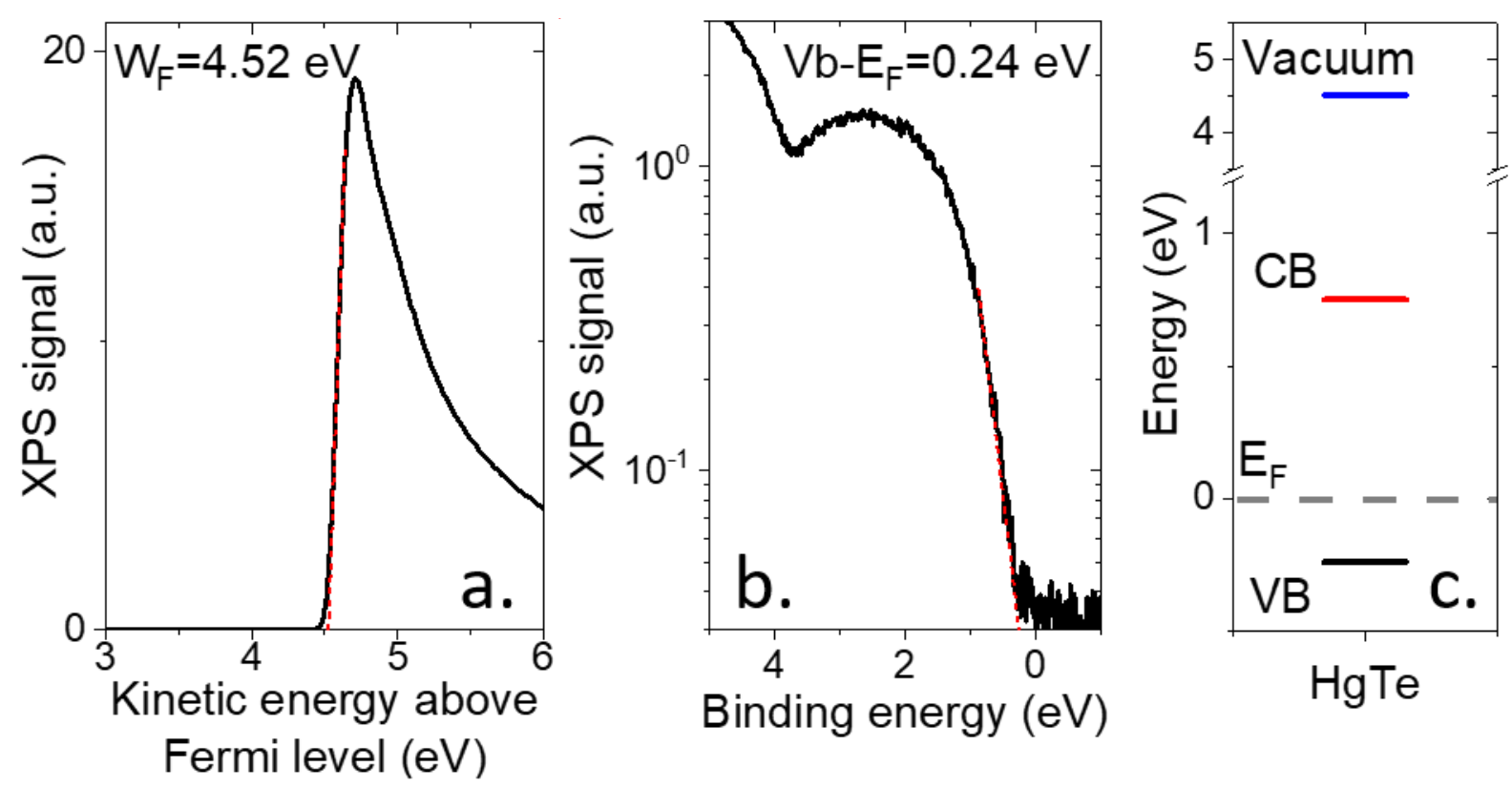

Figure $S 4$ a. Photoemission spectrum relative to the cut-off of the secondary electrons for a thin film made of HgTe CQDs capped with MPA. $b$. Photoemission spectrum relative to the valence band for a thin film of HgTe CQDs capped with MPA. c. Electronic spectrum in absolute energy scale for HgTe CQDs capped with MPA. The Fermi energy is set equal to zero. The black, red, and blue lines are respectively the valence band, the conduction band, and the vacuum level.

The analysis of the core levels of the HgTe sample is given in Figure S 5 . The overview spectrum displays a contribution of $\mathrm{C}$ in addition to the $\mathrm{Hg}$ and $\mathrm{Te}$ components. This $\mathrm{C}$ contribution comes from the thiol ligands used during synthesis (dodecanethiol) and to make the film conductive (mercaptoproprionic acid). Mercury ( $\mathrm{Hg} 4 \mathrm{f}$ state) presents two contributions (Figure $\mathrm{S} \mathrm{5b}$ ), as commonly observed for mercury chalcogenide nanocrystals. ${ }^{7-9}$ The main one appearing at $\mathrm{BE}=100.45 \mathrm{eV}$ is due to mercury coupled to telluride. The second one ${ }^{8}(\mathrm{BE}=101.1 \mathrm{eV})$ appearing at higher energy is a surface component and relates to surface excess mercury bonded to the thiol. The Te 4d state also displays two components appearing at 40.3 and 41 eV, see Figure S 5c 

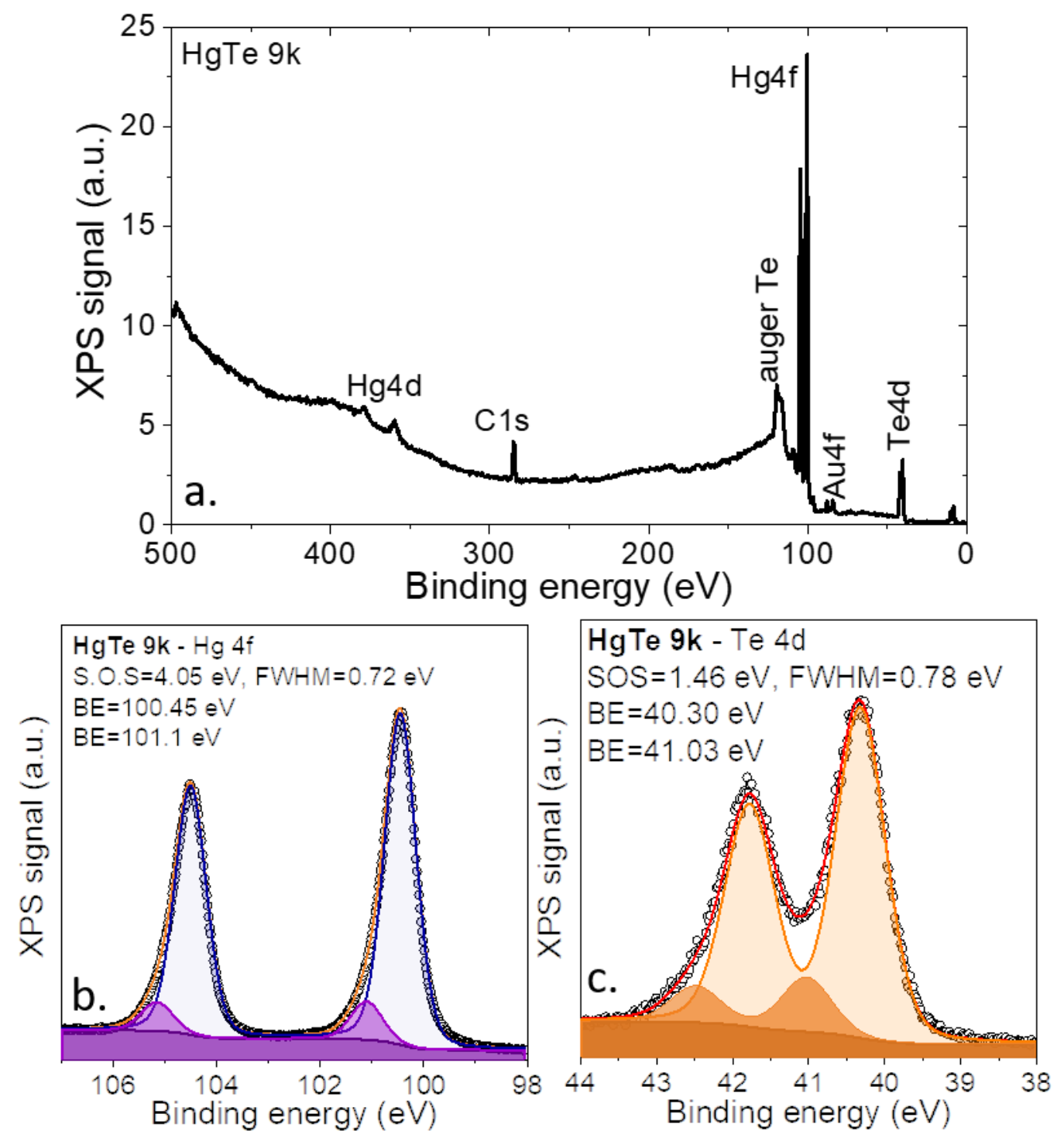

Figure $S 5$ a. X-ray photoemission overview spectrum relative to a thin film of MPA capped HgTe $C Q D s \mathrm{~b}$. Photoemission spectra relative to the $\mathrm{Hg} 4 \mathrm{f}$ state coming from $\mathrm{HgTe}$ CQDs with MPA as surface chemistry. c. Photoemission spectrum relative to the $\mathrm{Te} 4 \mathrm{~d}$ state coming from $\mathrm{HgTe}$ CQDs capped with MPA. 


\subsection{ZnO nanoparticles}

The synthesis was taken from Pradhan et al. ${ }^{10}$ Zinc acetate dihydrate $(2.95 \mathrm{~g})$ is dissolved in 125 $\mathrm{ml}$ of methanol under vigorous stirring and the temperature of the solution is set at $60{ }^{\circ} \mathrm{C}$. In a separate vial, $1.48 \mathrm{~g}$ of $\mathrm{KOH}(90 \%)$ is dissolved in $65 \mathrm{ml}$ of methanol. The $\mathrm{KOH}$ solution is added dropwise to the zinc acetate solution during $4 \mathrm{~min}$ at a constant temperature of $60^{\circ} \mathrm{C}$ with stirring. The reaction mixture is kept under the same conditions for the next $2.5 \mathrm{~h}$. In the end of the reaction, the heating mantle is removed, and the solution cooled down to room temperature naturally. The reaction mixture is separated in 4 falcons and centrifuged at $5000 \mathrm{rpm}$ for $2 \mathrm{~min}$. After trashing the supernatant, equal amount of methanol is added to mix with the pellet, and another centrifugation is conducted. After three rounds of purification, the NCs are dispersed in a mixed solvent with $2 \%$ butylamine in chloroform. The concentration of $\mathrm{ZnO}$ nanocrystals is set at $30 \mathrm{mg} \cdot \mathrm{mL}^{-1}$, and they are filtered through $0.22 \mu \mathrm{m}$ PTFE filter before use.

TEM image of the ZnO CQDs is given in Figure $S 6 a$ and shows a quasi-spherical shape. The absorption edge appears around $340 \mathrm{~nm}(3.65 \mathrm{eV})$, see Figure $S 6 b$. The $x$-ray diffraction is consistent with the wurtzite phase, see Figure $S 6 \mathrm{c}$. Fitting diffraction peak with the Scherrer's law leads to an estimated size of $8.3 \mathrm{~nm}$.
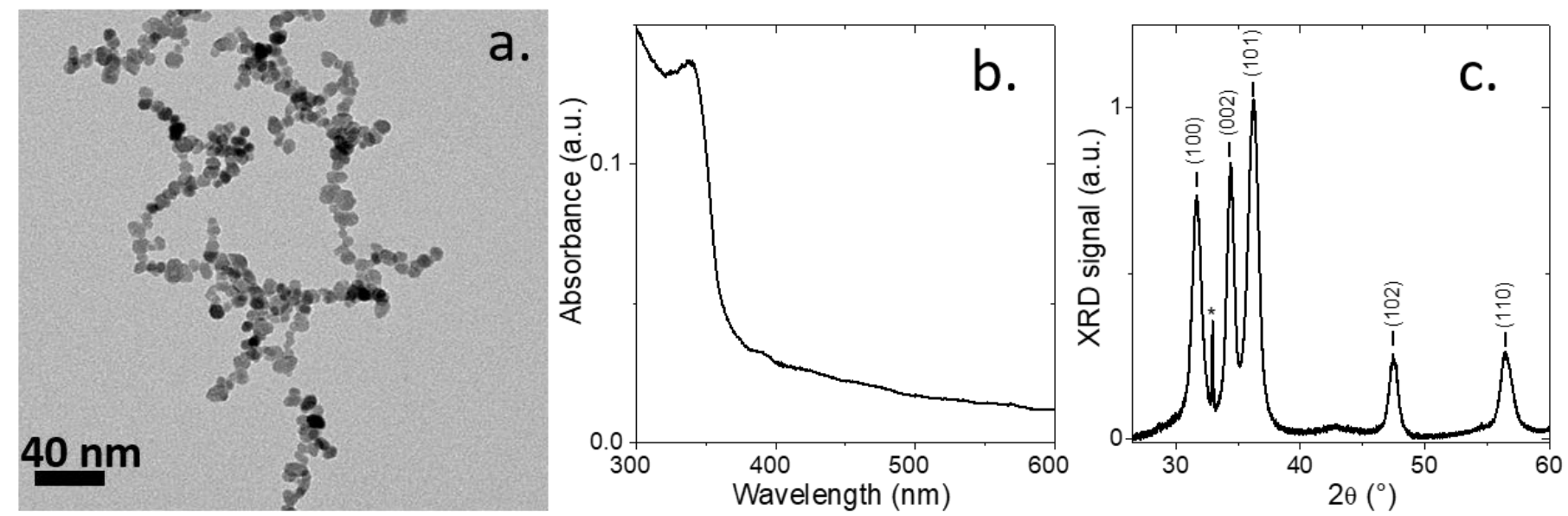

Figure $S 6$ a. Transmission electron microscopy image of ZnO NCs. b. Absorption spectrum of ZnO NCs. C. XRD diagram of wurtzite ZnO NCs. The peak ${ }^{*}$ corresponds to the Si substrate.
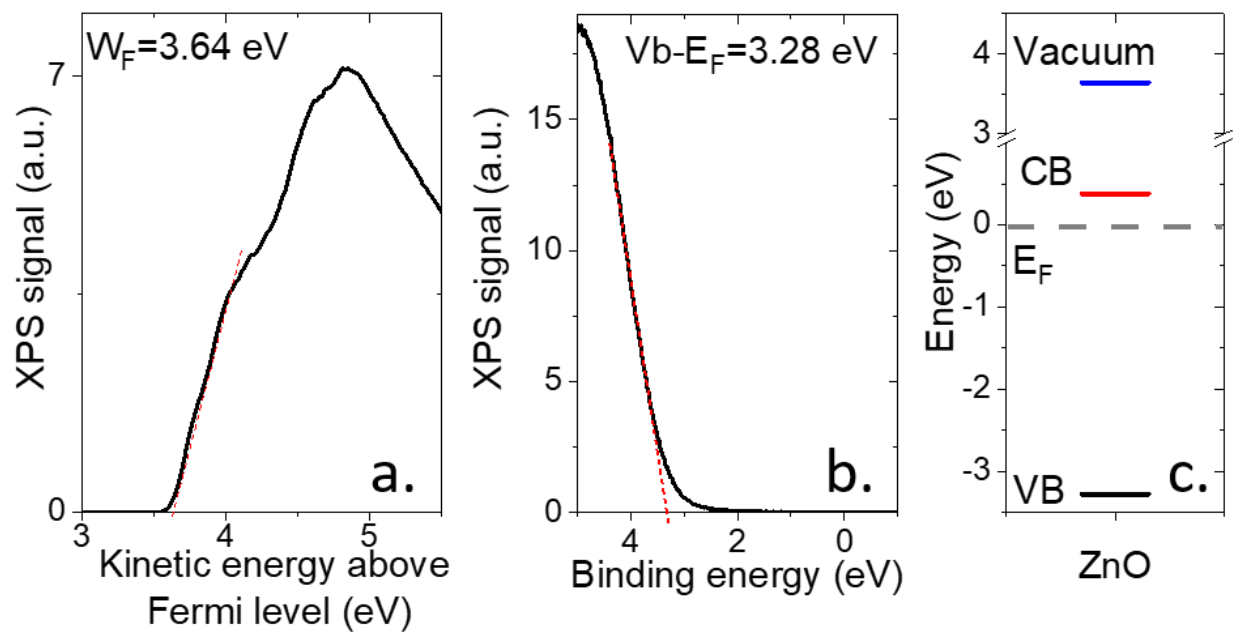
Figure $S 7$ a. Photoemission spectrum relative to the cut-off of the secondary electrons for a thin film made of ZnO CQDs. b. Photoemission spectrum relative to the valence band for a thin film consisting of ZnO CQDs. e. Electronic spectrum in absolute energy scale for ZnO CQDs. The Fermi energy is set equal to zero. The black, red, and blue lines are respectively the valence band, the conduction band, and the vacuum level.

From photoemission, we determine the work function of the $\mathrm{ZnO}$ to be $3.64 \mathrm{eV}$ (Figure S 7a), while the $\mathrm{V}_{\mathrm{b}}-\mathrm{E}_{\mathrm{F}}$ value is estimated to be $3.3 \mathrm{eV}$ (Figure $S 7 \mathrm{~b}$ ), suggesting a Fermi level close to the conduction band (Figure S 7c).

The analysis of the core levels for the $\mathrm{ZnO}$ sample is given in Figure $\mathrm{S}$ 8. The overview spectrum displays contribution of carbon in addition to the $\mathrm{Zn}$ and $\mathrm{O}$ components. This carbon contribution comes from the butylamine capping ligands. The zinc ( $\mathrm{Zn} 3 \mathrm{~d}$ state) mostly displays a single contribution at binding energy (BE) $10.63 \mathrm{eV}$, see Figure $\mathrm{S} 8 \mathrm{~b}$. The $\mathrm{O}$ 1s state presents two contributions. The first contribution with a $\mathrm{BE}$ of $530.8 \mathrm{eV}$ is resulting from stoichiometric $\mathrm{ZnO}$, while the second component at higher $\mathrm{BE}$ is often attributed to $\mathrm{ZnO}$ with oxygen vacancies.
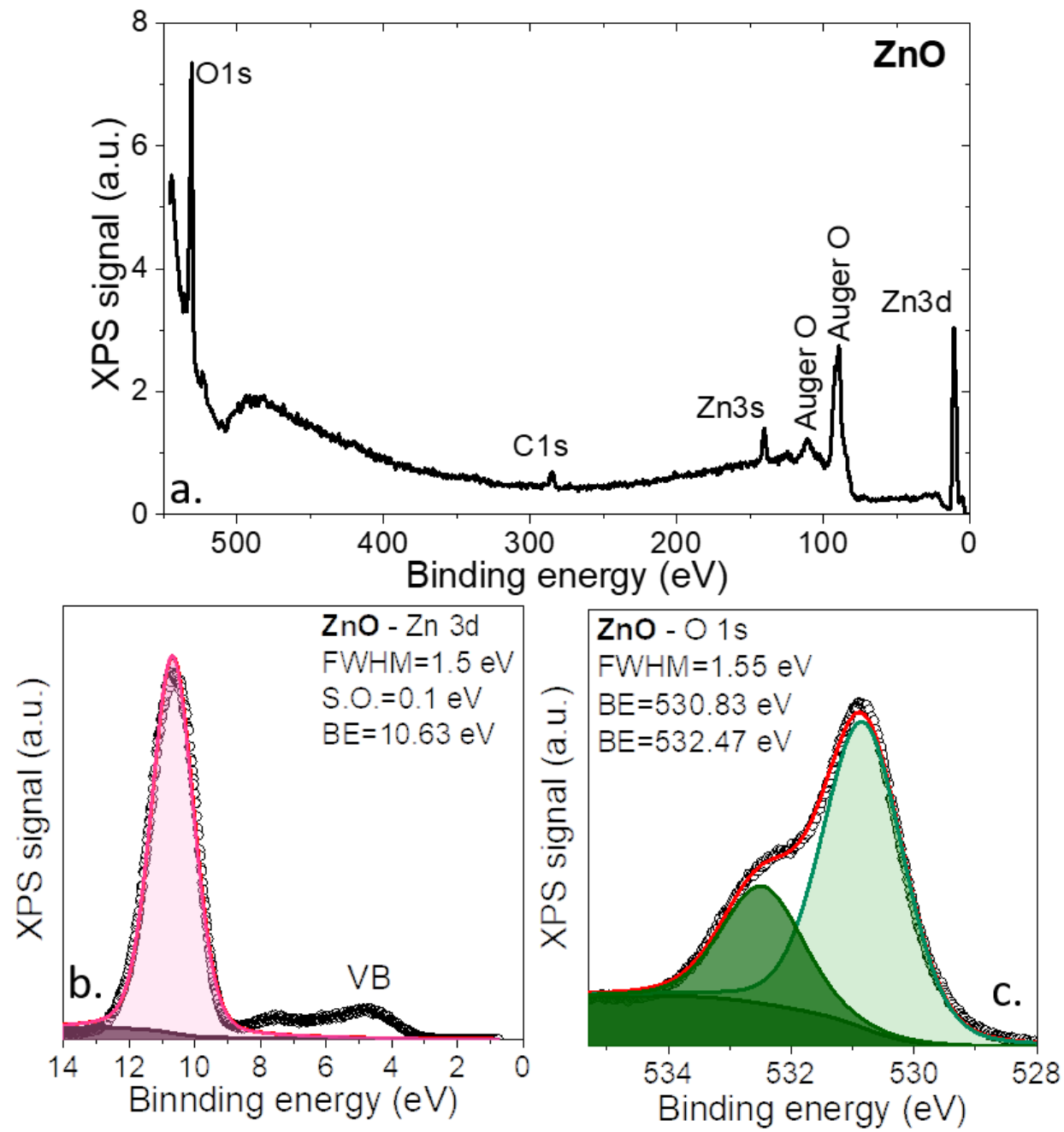

Figure $S 8$ a. X-ray photoemission overview spectrum relative to a thin film ZnO CQDs $b$. Photoemission spectra relative to the $\mathrm{Zn} 3 d$ state coming from $\mathrm{ZnO}$. c. Photoemission spectrum relative to the $O 1 s$ state coming from $Z n O C Q D s$. 


\subsection{PbS nanocrystals}

PbS nanocrystal synthesis: The procedure is inspired from Hines et al. ${ }^{11} 0.9 \mathrm{~g}$ of $\mathrm{PbO}$ were introduced in a $100 \mathrm{~mL}$ three neck flask with $3 \mathrm{~g}$ of OA and $47 \mathrm{~g}$ of ODE. The flask is degassed under vacuum at $120{ }^{\circ} \mathrm{C}$ for 2 hours. Meanwhile, in an air-free glove box, a mixture of $420 \mu \mathrm{L}$ of $\mathrm{TMS}_{2} \mathrm{~S}$ and $10 \mathrm{~mL}$ of ODE is prepared in a $20 \mathrm{~mL}$ vial, then introduced into a $20 \mathrm{~mL}$ syringe. The atmosphere of the flask is switched to $\mathrm{Ar}$ and the temperature is set equal to $90{ }^{\circ} \mathrm{C}$. The $\mathrm{TMS}_{2} \mathrm{~S}$ solution is quickly injected and the solution turned dark while the temperature drops to $80^{\circ} \mathrm{C}$. After $8 \mathrm{~min}$ at $80^{\circ} \mathrm{C}$, the reaction is stopped by removing the heating mantle and promptly cooling of the flask by the addition of a mixture of heptane and OA. The nanoparticles are then precipitated by the addition of ethanol. The formed pellet is redispersed in toluene. A second step of cleaning is repeated. Finally, the pellet is redispersed in toluene with a $50 \mathrm{mg} \cdot \mathrm{mL}^{-1}$ concentration. The solution is centrifuged to remove any colloidally unstable material. Finally, the solution is filtered on a 0.22 $\mu \mathrm{m}$ PTFE filter.

The absorption edge appears around $960 \mathrm{~nm}(1.3 \mathrm{eV})$, see Figure $\mathrm{S} 9 \mathrm{a}$. The material is also photoluminescent and the maximum of the emission is around $1100 \mathrm{~nm}$. The shape of the PbS particles is spherical according to TEM image (Figure $S 9 b$ ). Transport probed in a field effect transistor configuration shows a p-type transport (i.e. rise of the conductance under hole injection) when the nanoparticles are capped with EDT. ${ }^{12,13}$
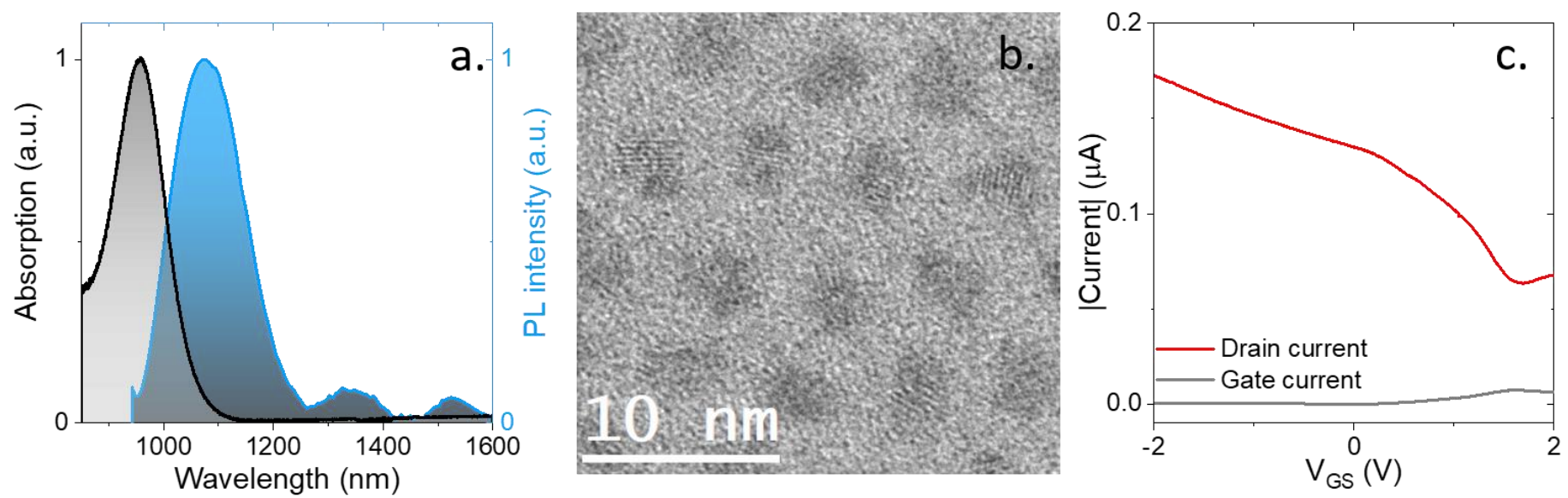

Figure $S 9$ a. Normalized absorption and PL intensity as a function of the wavelength for PbS nanocrystals. b. Transmission electron microscopy image of PbS NCs. c. Transfer curves (i.e. drain and source current as a function of gate bias) of PbS nanocrystals capped with EDT. The drain source bias is set at $400 \mathrm{mV}$.

From photoemission, we determine the work function of the $\mathrm{PbS}$ to be $4.3 \mathrm{eV}$ (Figure $\mathrm{S} 10 \mathrm{a}$ ), while the $\mathrm{V}_{\mathrm{b}}-\mathrm{E}_{\mathrm{F}}$ value is estimated to be $\approx 0.5 \mathrm{eV}$ (Figure $S 10 \mathrm{~b}$ ), this suggests a Fermi level in the bottom half of the band gap (Figure $S$ 10c). 

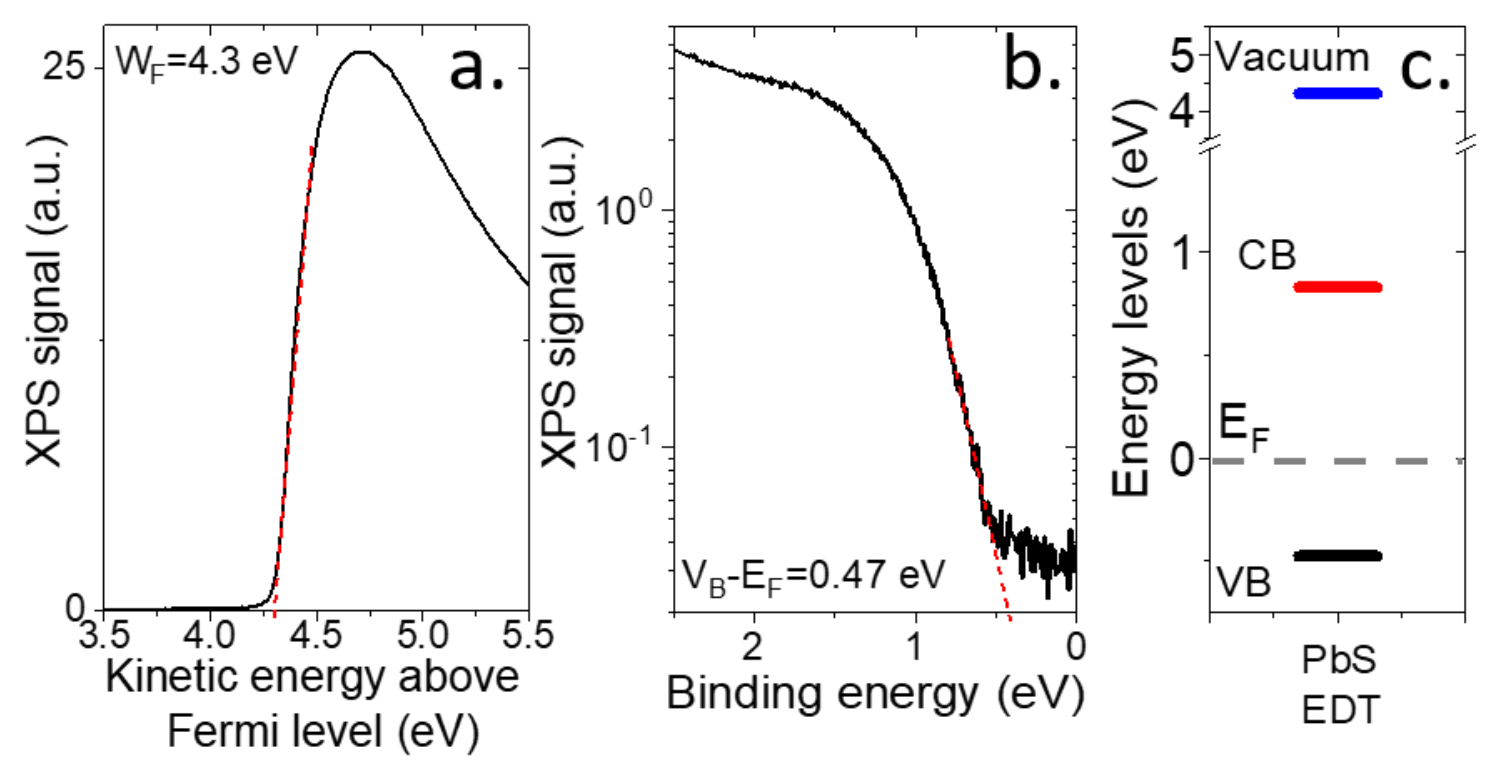

Figure $S 10$ Photoemission spectrum relative to the cut-off of the secondary electrons for a thin film made of PbS CQDs capped with EDT. b. Photoemission spectrum relative to the valence band for a thin film consisting of PbS CQDs capped with EDT. c. Electronic spectrum in absolute energy scale for PbS CQDs capped with EDT. The Fermi energy is set equal to zero. The black, red, and blue lines are respectively the valence band, the conduction band, and the vacuum level.

The analysis of the core levels for the PbS sample is given in Figure $\mathrm{S} 11$. The overview spectrum displays contribution of $\mathrm{C}$ and $\mathrm{O}$ in addition to the $\mathrm{Pb}$ and $\mathrm{S}$ components. This $\mathrm{C}$ and $\mathrm{O}$ contributions come from the native oleate ligands used during the synthesis. Lead ( $\mathrm{Pb} 4 \mathrm{f}$ state) presents two contributions. The main one appearing at $\mathrm{BE}=137.8 \mathrm{eV}$ is due to lead coupled to sulfide. A second weaker contribution is obtained at $\mathrm{BE}=138.8 \mathrm{eV}$ and is the result of partial oxidation of the nanoparticles. The $S 2 p$ also displays two components. The main one $(B E=160.9 \mathrm{eV})$ can be attributed to the sulfide in the PbS nanoparticles. The second one is the signature of the EDT ligands used to induce the p-type nature of the film. 

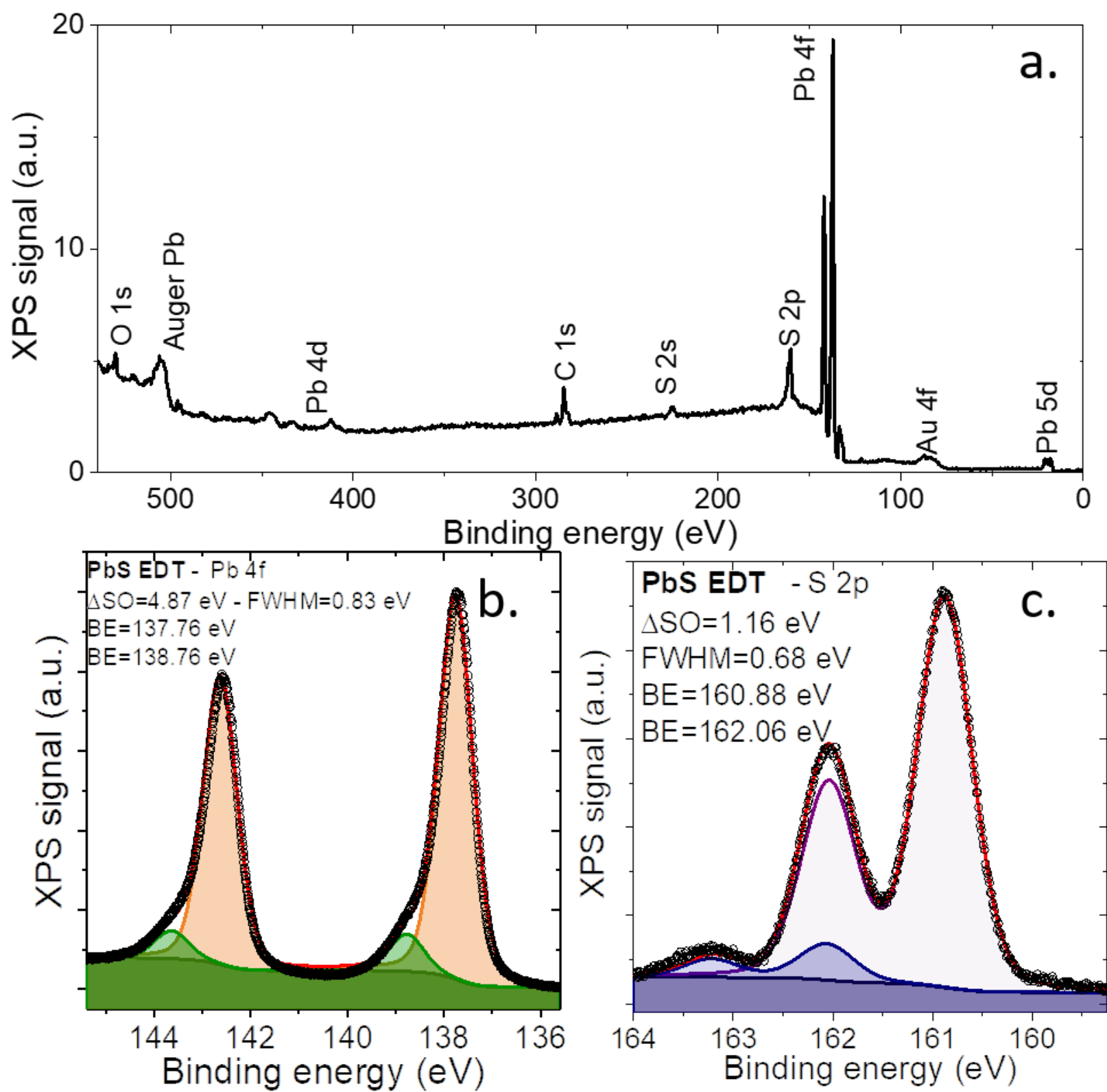

Figure $S 11$ a. $X$-ray photoemission overview spectrum relative to a thin film of EDT-capped PbS CQDs $b$. Photoemission spectra relative to the $P b 4 f$ state coming from PbS CQDs with EDT as surface chemistry. $c$. Photoemission spectrum relative to the $S 2 p$ state coming from PbS CQDs capped with EDT. 


\section{Material characterization}

\subsection{Structural characterization}

X-ray diffraction: XRD was obtained by drop-casting the considered solution of CQDs onto a $\mathrm{Si}$ wafer. Measurements were made on Philips X'pert diffractometer, operated at $40 \mathrm{kV}$ and $40 \mathrm{~mA}$. The mission relies on the $\mathrm{Cu} \mathrm{K}_{\alpha}$ line at $\lambda=0.154 \mathrm{~nm}$

TEM: A drop of a diluted nanocrystals solution was drop-casted on a copper grid covered with an amorphous carbon film. The grid was degassed overnight under secondary vacuum. Imaging was conducted using a JEOL 2010 transmission electron microscope operated at $200 \mathrm{kV}$.

\subsection{Spectroscopic characterization}

UV-Vis spectrum of nanocrystal solution was recorded using a JASCO V-730 spectrometer. When a combination of UV and NIR measurement was required, we use a Shimadzu 3600 UV-Vis-NIR.

Infrared spectroscopy was conducted using a Fisher IS50 Fourier transform Infrared spectrometer. To measure CQD absorption, we use the spectrometer in ATR configuration. A drop of CQD solution was dried onto the diamond cell. The source was a white light, the beam splitter is made of $\mathrm{CaF}_{2}$ and the detector is a DTGS ATR. Spectra are typically acquired between $12000 \mathrm{~cm}^{-}$ 1 and $2000 \mathrm{~cm}^{-1}$ with a $4 \mathrm{~cm}^{-1}$ resolution while averaging over 32 spectra.

Photoluminescence quantum yield (PLQY) of HgTe nanocrystals in solution was obtained by an Edinburgh Instrument spectrometer equipped with an integrating sphere. The samples were excited at $900 \mathrm{~nm}$ with a Xe lamp, and the photons were collected with an InGaAs detector cooled by $\mathrm{N}_{2}$. $\mathrm{HgTe}$ nanocrystals were dispersed in tetrachloroethylene to decrease the absorption of the solvent. A series of solutions with optical density from 0.09 to 0.21 at $900 \mathrm{~nm}$ were measured. For measurements on film, we excite the film with a blue (405 $\mathrm{nm}$ below $\mathrm{ZnO}$ band edge) laser, we collect the PL signal on a Flame NIR Spectrometer equipped with an InGaAS detector and the signal is normalized by the absorbance of the film at the excitation wavelength.

Time resolved photoluminescence (TRPL) experiments were performed at room temperature on solution diluted nanocrystals drop-casted on a silicon substrate. The samples were excited using a mode-locked Ti-sapphire laser (Tsunami from Spectra Physics) with a 1.5 ps pulse width and a wavelength at $780 \mathrm{~nm}$. A pulse picker was used to reduce the repetition rate from $80 \mathrm{MHz}$ to 800 $\mathrm{kHz}$. The near-infrared TRPL was dispersed by a spectrometer (SpectraPro HRS $500 \mathrm{~mm}$ from Princeton Instruments) which exit can be either sent to an InGaAs camera to obtain continuous wave-like emission spectra or coupled to a single-mode optical fiber. The fiber was connected to a superconducting nanowire single photon detector (Single Quantum) in combination with a timecorrelated single photon counting system (PicoHarp from PicoQuant). The temporal shape of the detected luminescence signal was acquired as a histogram made of 65000 bins with a bin width of 
$32 \mathrm{ps}$. The Instrument-Response Function (IRF) width of the overall setup is in the order of $1.5 \mathrm{~ns}$. The excitation average power was kept at $1,33 \mu \mathrm{W}$ at $800 \mathrm{kHz}$ with a laser spot diameter of $\approx 100$ $\mu \mathrm{m}$.
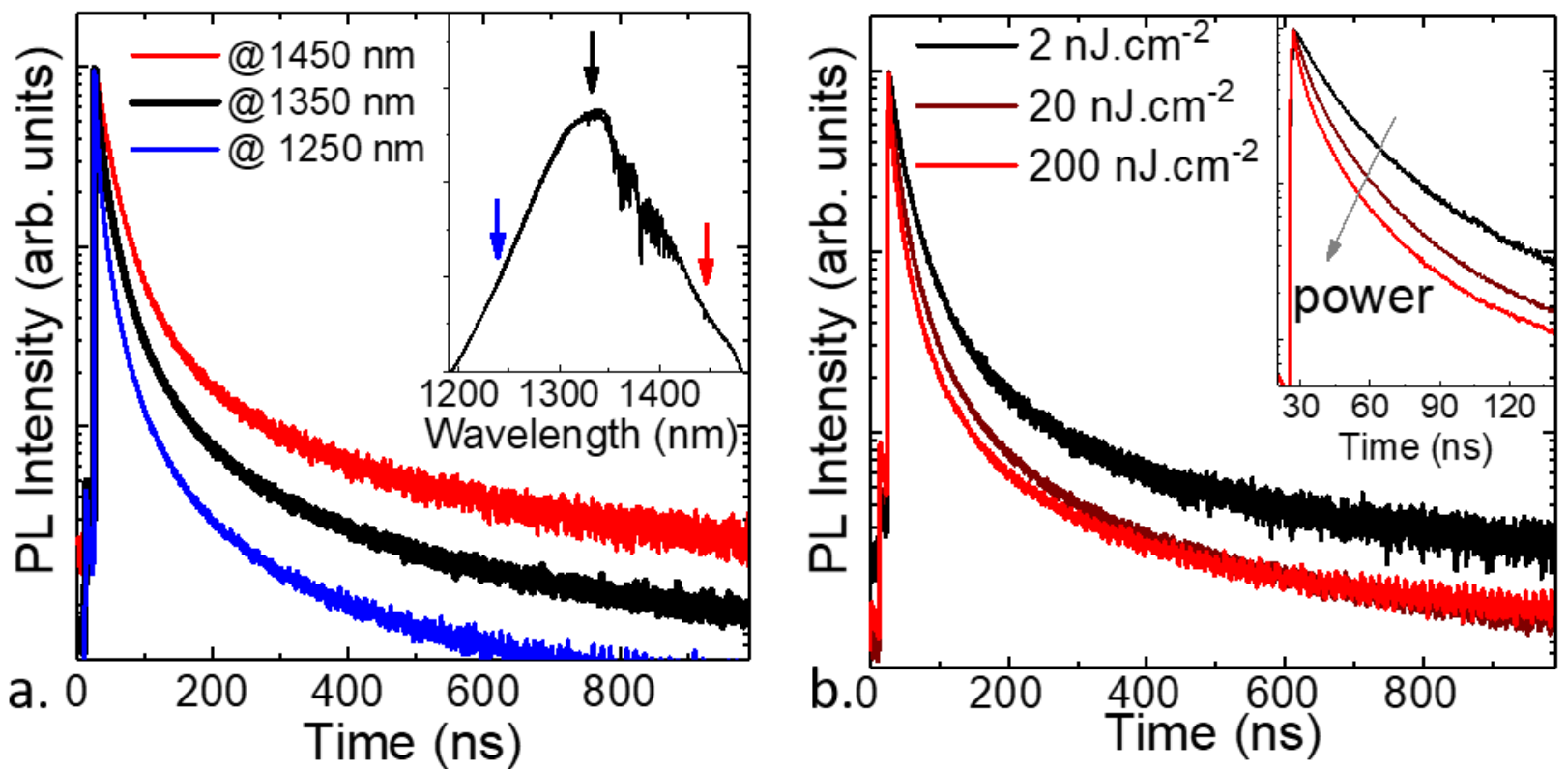

Figure S 12 a. PL dynamics of HgTe NCs measured at three different wavelengths within the spectrum shown as arrows in the Inset (the laser pump fluence is $20 \mathrm{~nJ}^{\mathrm{cm}} \mathrm{cm}^{-2}$ ). b. PL dynamics of HgTe NCs measured at $1350 \mathrm{~nm}$ for three different laser pump fluences (2, 20 and $200 \mathrm{~nJ} . \mathrm{cm}^{-2}$ ).

Figure $\mathrm{S} 12 \mathrm{a}$ displays the PL dynamics of $\mathrm{HgTe} \mathrm{NCs}$ for three detected wavelengths within the spectrum (1250, 1350 and $1450 \mathrm{~nm}$, respectively). As expected, we observe longer decay times for the larger detected wavelengths. This is consistent with the possible influence of the recombinations involving localized states at low energy ${ }^{1}$. In Figure S 12b, the PL kinetics of the HgTe NCs are displayed for three laser excitations $\left(2,20\right.$ and $\left.200 \mathrm{~nJ} / \mathrm{cm}^{-2}\right)$; the detected wavelength corresponds to the PL peak ( $\approx 1350 \mathrm{~nm}$ ). Shorter decay times are evidenced for larger photogenerated carrier densities as a consequence of possible Auger effects ${ }^{14}$. 


\subsection{Photoelectron spectroscopy}

Energy dispersive X-ray spectroscopy: A film of nanocrystals was deposited onto a Si substrate by spin-coating. A Zeiss Supra 40 scanning electron microscope was used to acquire the SEM images. The EDX acquisition was made using a Brucker Quantax EDX XFlash 6/30. The acceleration bias was set to $3 \mathrm{kV}$ and the aperture at $120 \mu \mathrm{m}$. The acceleration bias was set low to reduce the Si peak from the substrate.

X-ray photoemission measurements (XPS): For photoemission spectroscopy, we use the Tempo beamline of synchrotron Soleil. Films of nanocrystals were spin-casted onto a gold coated $\mathrm{Si}$ substrate (gold layer is $80 \mathrm{~nm}$ thick). The ligands of the nanocrystals were exchanged using the same procedure as for transport measurement to avoid any charging effect during measurements. Samples were introduced in the preparation chamber and degassed until vacuum below $10^{-9} \mathrm{mbar}$ is reached. Then samples were introduced in the analysis chamber. The signal was acquired onto a MBS $A^{-1}$ photoelectron analyzer equipped with a delay line detector developed by Elettra. ${ }^{15}$ Acquisition was done at constant pass energy $(50 \mathrm{eV})$ within the detector. Photons energy of 150 $\mathrm{eV}$ was used for acquisition of valence band and work function while a $600-\mathrm{eV}$ photon energy was used for the analysis of the core level

Calibration procedure: A gold substrate was used to calibrate the Fermi energy. The absolute value of the incoming photon energy is determined by measuring the second order of Au core level peaks. From this calibrated energy scale, we measure the energy of the Au $4 f$ from the gold on the manipulator. This will later serve as reference to measure the exact photon energy every time the incident photon energy is tuned. Note that to measure the work function, we apply an $18 \mathrm{~V}$ bias, which exact value has been determined by measuring the shift of a Fermi edge. 


\subsection{Transport measurements}

Electrodes fabrication for transistor: A polished $\mathrm{Si} / \mathrm{SiO}_{2}$ substrate was first rinsed and then sonicated in acetone for $5 \mathrm{~min}$. The wafer was then rinsed with acetone and isopropanol and finally was conducted by plasma cleaning for 5 min. Then AZ 5214E resist was spin coated on the substrate and baked at $110^{\circ} \mathrm{C}$ for $90 \mathrm{~s}$. The resist was exposed through a shadow mask to UV illumination for $2 \mathrm{~s}$, with black paper below the substrate. The resist was baked again at $125^{\circ} \mathrm{C}$ for 2 min and re-exposed to UV (without the mask) for $40 \mathrm{~s}$. The resist was then developed using AZ726. The film was rinsed with water and finally dried. The remaining organic layer was removed by plasma cleaning. $5 \mathrm{~nm}$ of chromium and $80 \mathrm{~nm}$ of gold were evaporated and the remaining resist was removed by immersing the film in acetone for one hour. The electrodes were then rinsed with isopropanol and finally dried. The interdigitated electrodes include 25 digits, each $2.5 \mathrm{~mm}$ long with a $20-\mu \mathrm{m}$ gap between them. The optical area of the device is $0.037 \mathrm{~cm}^{2}$.

Electrolyte gating: For electrolyte gating we first mixed in a glove box $0.5 \mathrm{~g}$ of $\mathrm{LiClO}_{4}$ with $2.3 \mathrm{~g}$ of PEG $\left(\mathrm{Mw}_{w}=6 \mathrm{~kg} \cdot \mathrm{mol}^{-1}\right)$. The vial was heated at $170^{\circ} \mathrm{C}$ on a hot plate for $2 \mathrm{~h}$ until the solution turned clear. The electrolyte solution was warmed to around $100^{\circ} \mathrm{C}$ and brushed on the top of the NCs film.

Thin film deposition and ligand exchange: The thin films for transport measurement were deposited by spin coating. The $30 \mathrm{mg} \cdot \mathrm{mL}^{-1}$ solution prepared for the LED fabrication was used. After the spin coating of the first layer, the sample was dipped in a $0.5 \%$ MPA solution in methanol for 3 min to allow the ligand exchange. Then the film was rinsed in methanol for $30 \mathrm{~s}$. The above process was repeated once more to fill the cracks induced by the previous ligand exchange. The overall thickness of the film was $60-80 \mathrm{~nm}$.

Transistor Measurement: The sample was connected to a Keithley 2634b, which set the drain source bias ( $\left.V_{D S}\right)$, controled the gate bias (VGS) with a step of $1 \mathrm{mV}$ and measured the associated currents (IDS and IGS). 


\subsection{Investigation of the $\mathrm{HgTe} / \mathrm{ZnO}$ mixture}

This section is dedicated to the investigation of the emitting layer of the diode which is made of a $\mathrm{HgTe} / \mathrm{ZnO}$ mixture.

\section{- Material composition}

Figure S 13 and Table S 1 provide the result of the Energy dispersive $X$-ray spectroscopy for mixture made of $\mathrm{HgTe}$ and $\mathrm{ZnO}$ CQDs with various $\mathrm{HgTe}$ content. In the whole paper the ratio of $\mathrm{HgTe}$ and $\mathrm{ZnO}$ are discussed from volume ratio used to obtain the mixture. From X-ray diffraction, we have extracted the size of the $\mathrm{ZnO}(8.3 \mathrm{~nm})$ and $\mathrm{HgTe}(4 \mathrm{~nm})$. This means $\mathrm{HgTe}$ CQDs include 510 atoms, while the $\mathrm{ZnO}$ have around 4180 atoms per particle. Based on these values we can convert the volume ratio into particle ratio, see Table $S 1$. The $25-50 \%$ range which appears to be the optimal value for LED performance correspond to roughly $1: 1 \mathrm{HgTe}$ to $\mathrm{ZnO}$ ratio

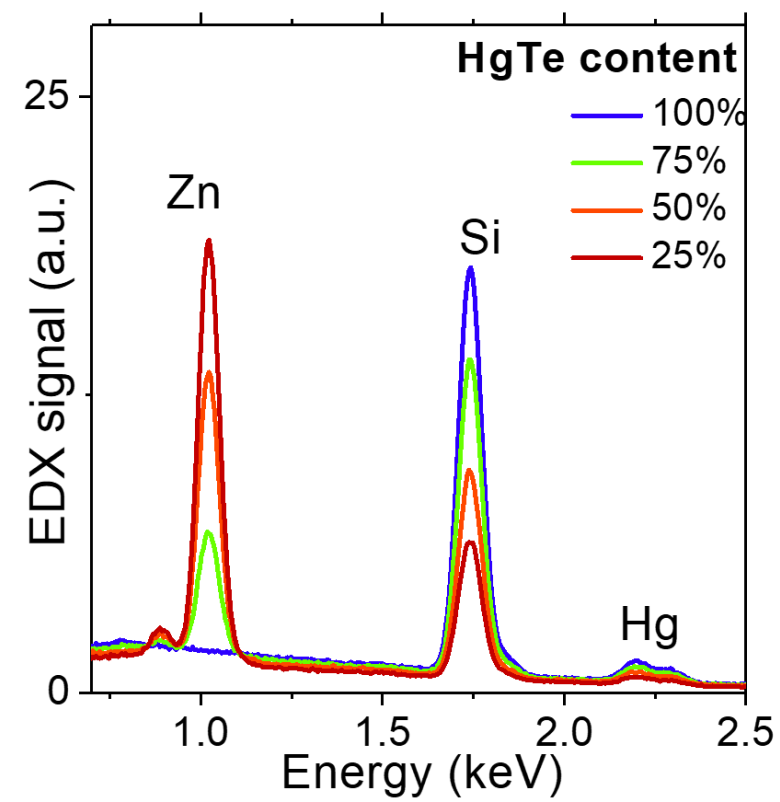

Figure $S 13$ Energy dispersive $X$-ray spectroscopy spectra relative to mixture made of $\mathrm{HgTe}$ and ZnO CQDs with various HgTe content.

Table S 1 atomic and nanocrystal ratio for mixture made of $\mathrm{HgTe}$ and $\mathrm{ZnO}$ CQDs with various $\mathrm{HgTe}$ content.

\begin{tabular}{lllll}
\hline $\begin{array}{l}\text { HgTe } \\
\text { volume } \\
\text { ratio }\end{array}$ & $\begin{array}{l}\mathrm{Hg} \\
(\%)\end{array}$ & $\begin{array}{l}\mathrm{Zn} \\
(\%)\end{array}$ & $\begin{array}{l}\text { Atom } \\
\mathrm{Zn} / \mathrm{Hg}\end{array}$ & $\begin{array}{l}\mathrm{HgTe} / \mathrm{NPO} \\
\mathrm{NP}\end{array}$ \\
\hline $100 \%$ & 2.25 & & & \\
\hline $75 \%$ & 2.01 & 4.57 & 2.27 & 3.68 \\
\hline $50 \%$ & 1.7 & 12.62 & 7.42 & 1.23 \\
\hline $25 \%$ & 1.52 & 19.31 & 12.7 & 0.66 \\
\hline
\end{tabular}


The absorption spectra of the $\mathrm{HgTe} / \mathrm{ZnO}$ mixture are displayed in Figure $\mathrm{S} 14$. We can observe in the near-IR at $1200 \mathrm{~nm}$ the band-edge of $\mathrm{HgTe}$, while the band-edge of $\mathrm{ZnO}$ comes as a discontinuity in the curve at $340 \mathrm{~nm}$. The absorption spectra of the mixture are the weighted sum of their two components. This suggests a limited interaction of the two materials.

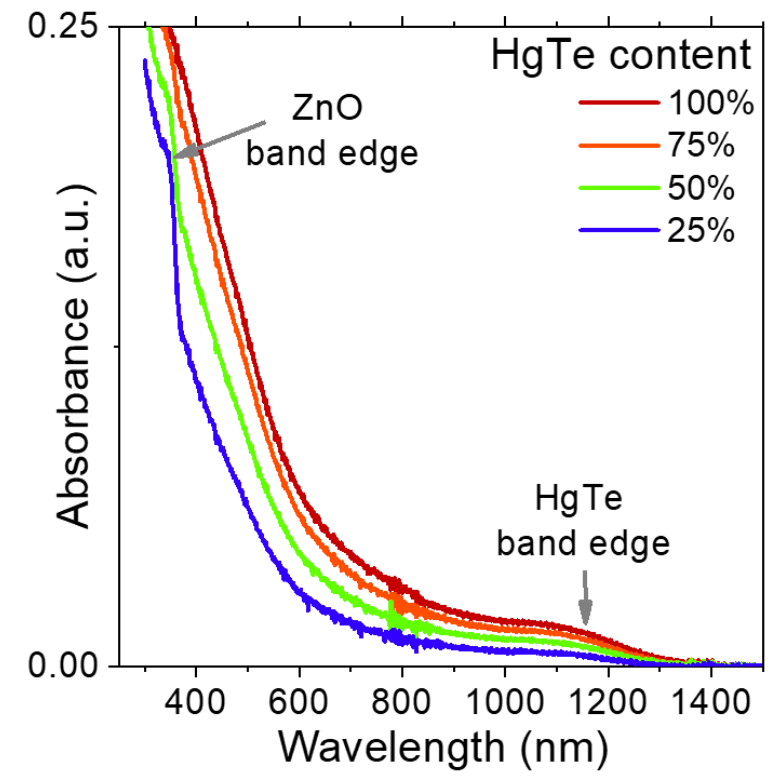

Figure S 14 Absorption spectra of mixture made of HgTe and ZnO CQDs with various HgTe content.

\section{- Electronic spectroscopy}

From Figure S 15 to Figure S 20, we analyze systematically the cut-off of the secondary electrons (for work function determination), valence band and core levels $(\mathrm{Hg} 4 \mathrm{f}, \mathrm{Te} 4 \mathrm{~d}, \mathrm{Zn} 3 \mathrm{~d}$ et $\mathrm{O} 1 \mathrm{~s}$ ) relative to three different ratio of $\mathrm{HgTe} / \mathrm{ZnO}$ mixtures.

○ $\mathrm{HgTe}(75 \%) / Z n O$ mixture
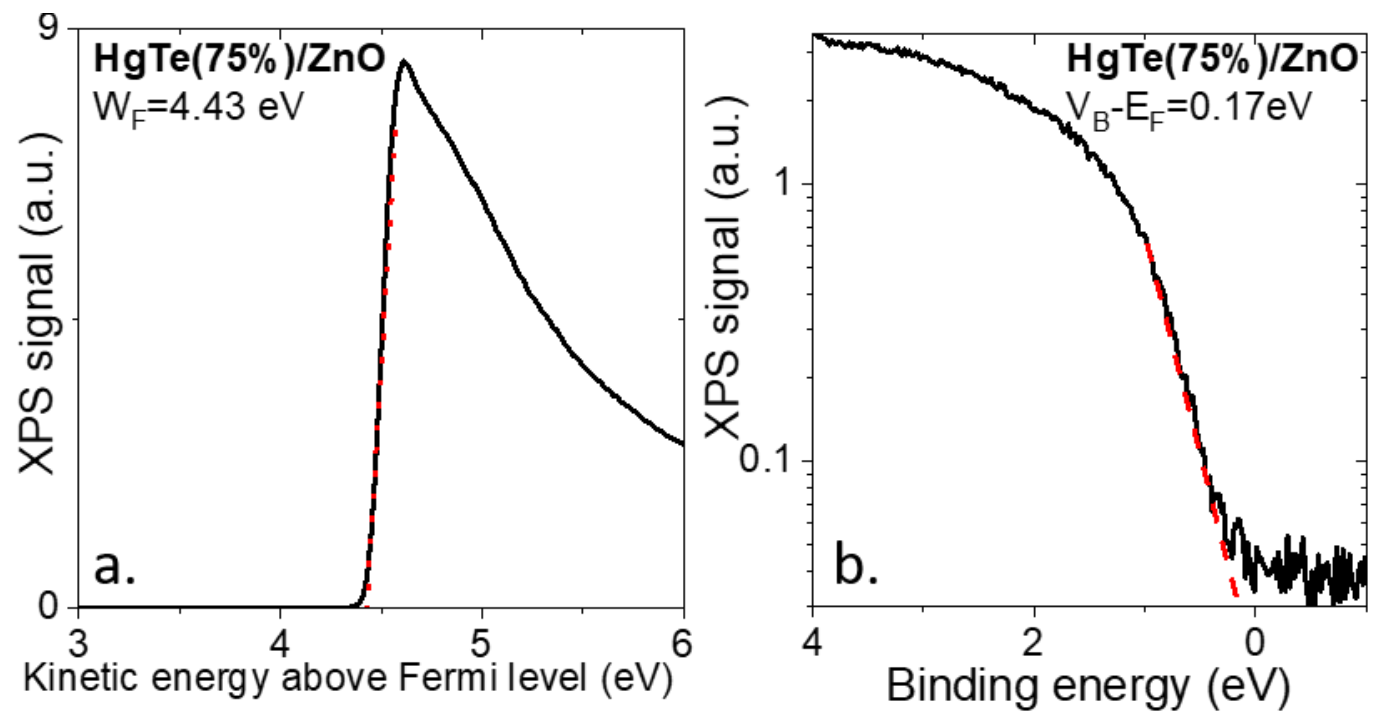

Figure $S 15$ a. Photoemission spectrum relative to the cut-off of the secondary electrons for a thin film made of $\mathrm{HgTe}(75 \%) / Z n O ~ C Q D s$ mixture. b. Photoemission spectrum relative to the valence band for a thin film consisting of a thin film made of $\mathrm{HgTe}(75 \%) / \mathrm{ZnO} C Q D s$ mixture. 

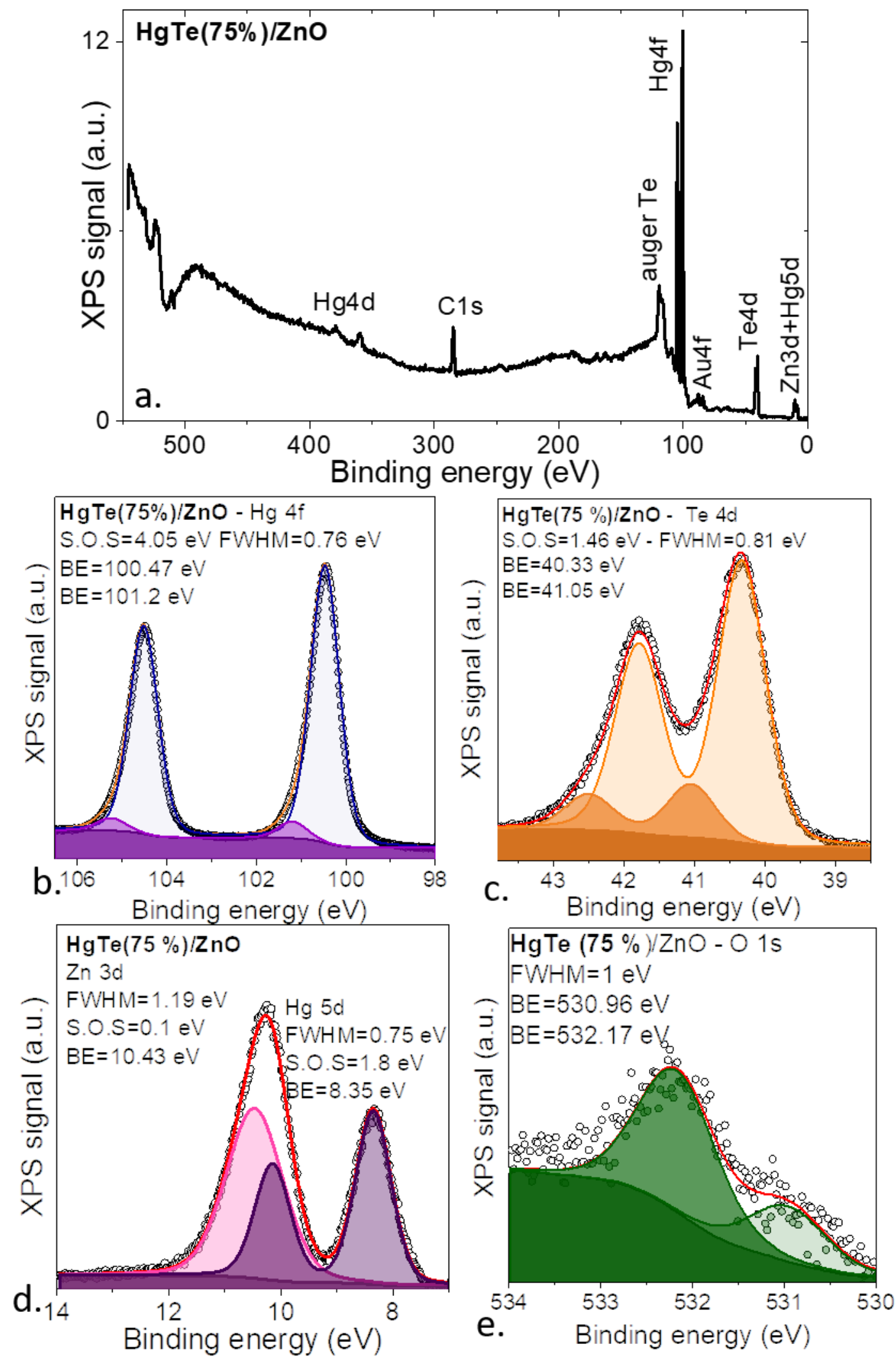

Figure S 16 a. X-ray photoemission overview spectrum for a thin film made of $\mathrm{HgTe}(75 \%) / \mathrm{ZnO}$ CQDs mixture. b. Photoemission spectrum relative to the $\mathrm{Hg} 4 \mathrm{f}$ state coming from a thin film made of $\mathrm{HgTe}(75 \%) / Z n O$ CQDs mixture. $\mathrm{C}$. Photoemission spectrum relative to the $\mathrm{Te} 4 \mathrm{~d}$ state coming from a thin film made of $\mathrm{HgTe}(75 \%) / Z n O C Q D s$ mixture. $d$. Photoemission spectrum relative to the $\mathrm{Zn} 3 d$ state coming from a thin film made of $\mathrm{HgTe}(75 \%) / Z n O$ CQDs mixture. e. Photoemission spectrum relative to the $\mathrm{O} 1 \mathrm{~s}$ state coming from a thin film made of $\mathrm{HgTe}(75 \%) / \mathrm{ZnO} C Q D$ s mixture. 
○ HgTe (50\%)/ZnO mixture

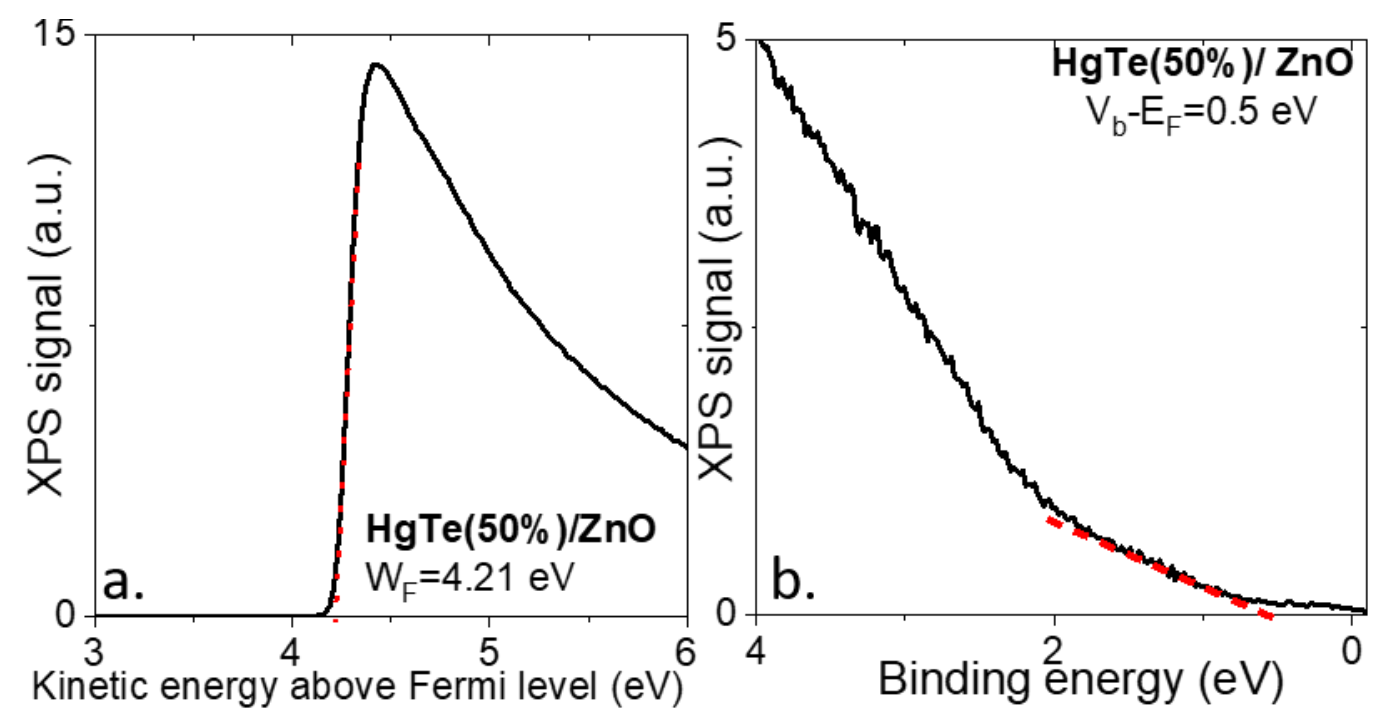

Figure $S 17$ a. Photoemission spectrum relative to the cut-off of the secondary electrons for a thin film made of $\mathrm{HgTe}(50 \%) / \mathrm{ZnO}$ CQDs mixture. b. Photoemission spectrum relative to the valence band for a thin film consisting for a thin film made of $\mathrm{HgTe}(50 \%) / \mathrm{ZnO}$ CQDs mixture. 

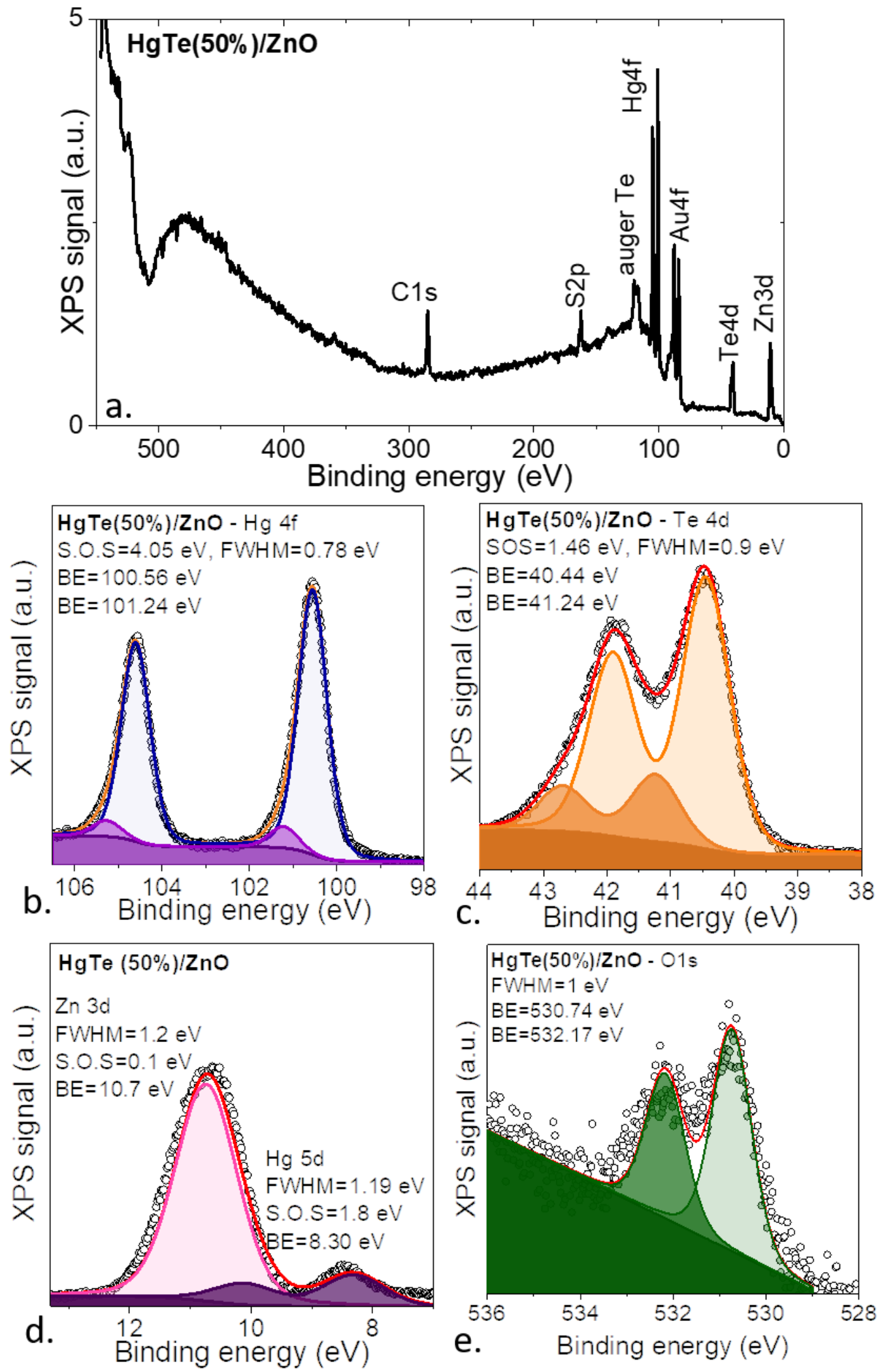

Figure S 18 a. X-ray photoemission overview spectrum for a thin film made of $\mathrm{HgTe}(50 \%) / \mathrm{ZnO}$ CQDs mixture. b. Photoemission spectrum relative to the $\mathrm{Hg} 4 \mathrm{f}$ state coming from a thin film made of $\mathrm{HgTe}(50 \%) / \mathrm{ZnO}$ CQDs mixture. c. Photoemission spectrum relative to the $\mathrm{Te} 4 \mathrm{~d}$ state coming from a thin film made of $\mathrm{HgTe}(50 \%) / Z n O C Q D s$ mixture. $d$. Photoemission spectrum relative to the $\mathrm{Zn} 3 d$ state coming from a thin film made of $\mathrm{HgTe}(50 \%) / \mathrm{ZnO} C Q D$ s mixture. e. Photoemission spectrum relative to the $\mathrm{O}$ 1s state coming from a thin film made of $\mathrm{HgTe}(50 \%) / \mathrm{ZnO} C Q D$ s mixture 

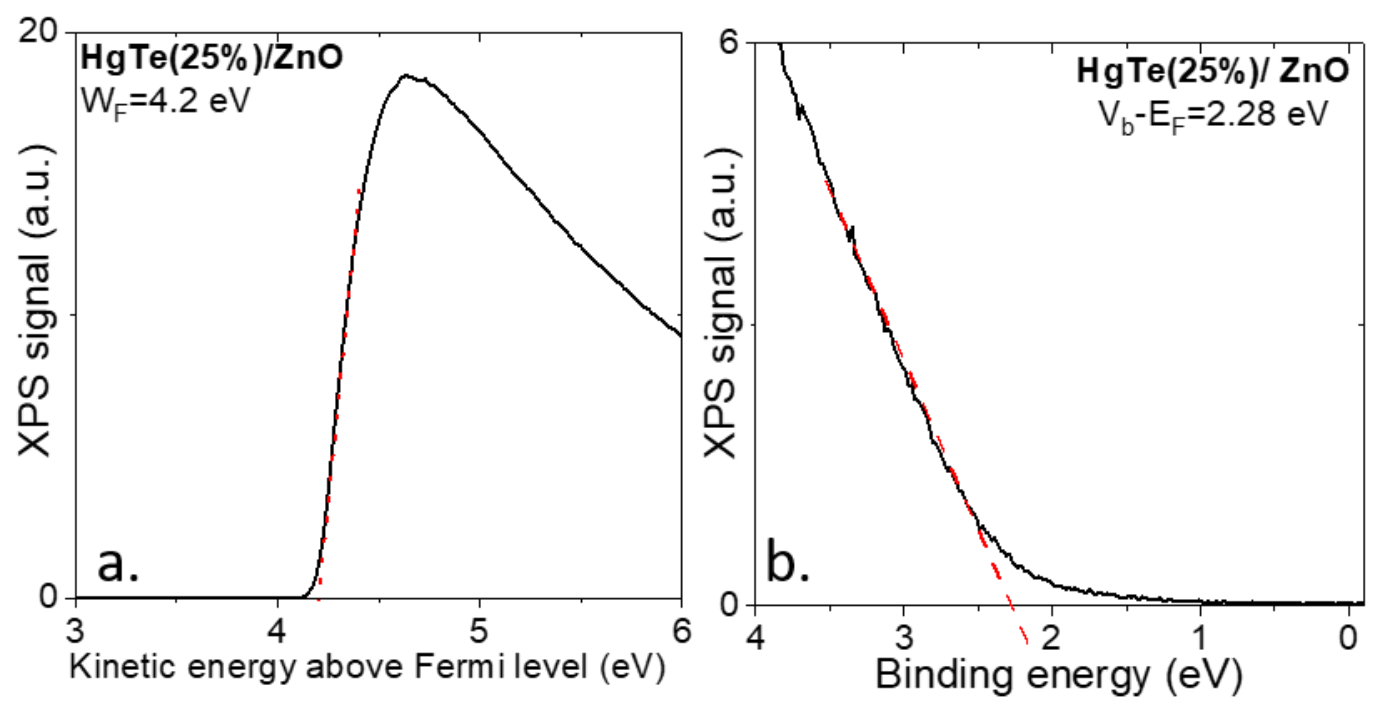

Figure $S 19$ a. Photoemission spectrum relative to the cut-off of the secondary electrons for a thin film made of HgTe (25\%)/ZnO CQDs mixture. b. Photoemission spectrum relative to the valence band for a thin film consisting for a thin film made of $\mathrm{HgTe}(25 \%) / Z n O C Q D s$ mixture. 

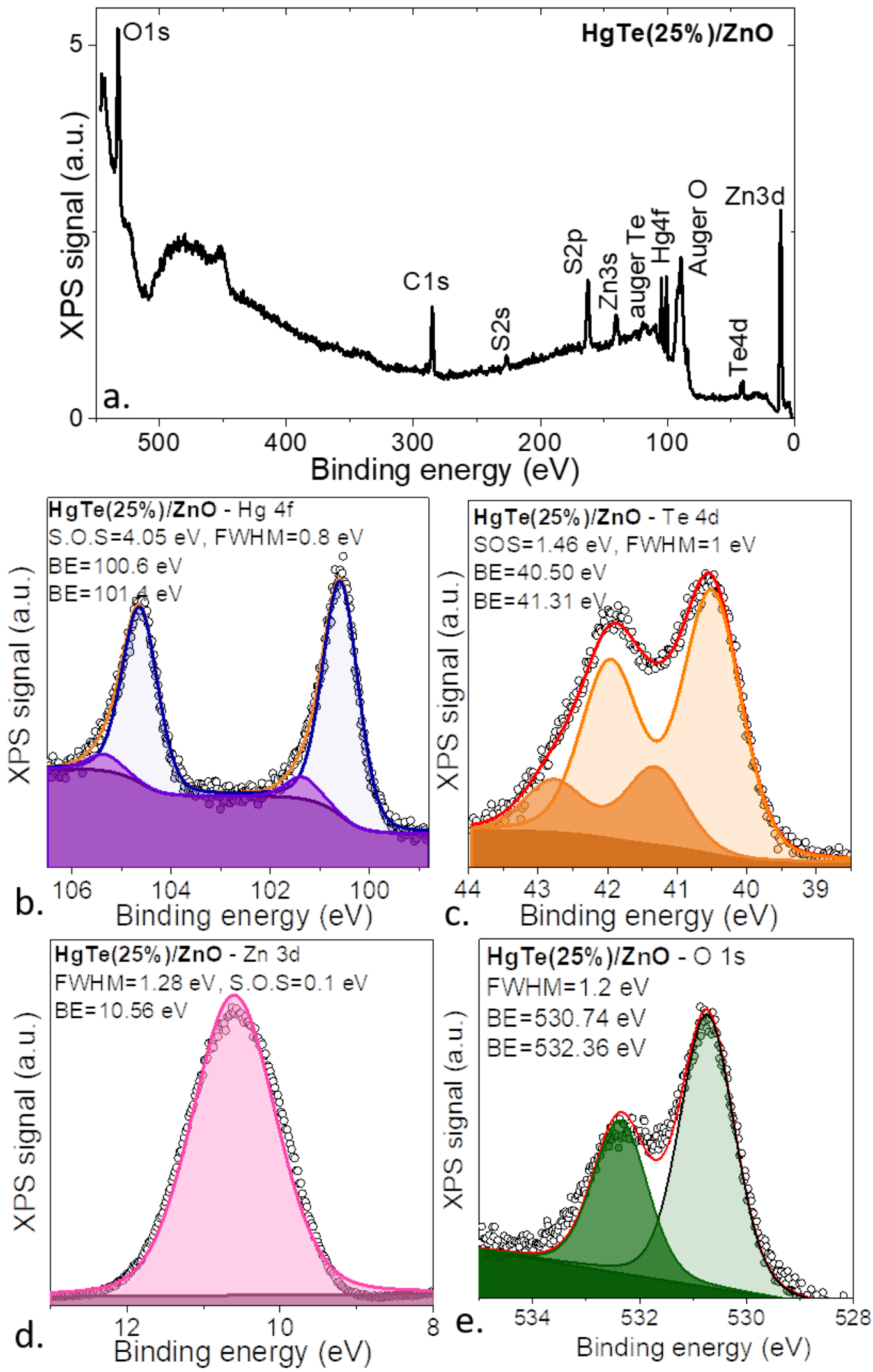

Figure S 20a. X-ray photoemission overview spectrum for a thin film made of $\mathrm{HgTe}(25 \%) / \mathrm{ZnO}$ $C Q D s$ mixture. b. Photoemission spectrum relative to the $\mathrm{Hg} 4 \mathrm{f}$ state coming from a thin film made of $\mathrm{HgTe}(25 \%) / Z n O$ CQDs mixture. c. Photoemission spectrum relative to the $\mathrm{Te} 4 \mathrm{~d}$ state coming from a thin film made of $\mathrm{HgTe}(25 \%) / Z n O C Q D s$ mixture. $d$. Photoemission spectrum relative to the $\mathrm{Zn} 3 d$ state coming from a thin film made of $\mathrm{HgTe}(25 \%) / \mathrm{ZnO} C Q D s$ mixture. e. Photoemission spectrum relative to the $\mathrm{O} 1 \mathrm{~s}$ state coming from a thin film made of $\mathrm{HgTe}(25 \%) / \mathrm{ZnO} C Q D$ s mixture. 
For the mixture of $\mathrm{HgTe} / \mathrm{ZnO}$ the signal relative to the valance band combines two possible shifts: one is from the doping of the $\mathrm{ZnO}$ by the $\mathrm{HgTe}$ and the other one is from the appearing of the $\mathrm{HgTe}$ states in the vicinity of the Fermi level. Thus, valence band only, cannot be used to reveal band bending and charge transfer. In Figure S 21, we have compared the photoemission peak relative to the $\mathrm{Hg} 4 \mathrm{f}$ for different $\mathrm{HgTe}$ ratio in a $\mathrm{HgTe} / \mathrm{ZnO}$ CQD mixture. We observe a small shift (150 meV) toward higher binding energy for the $\mathrm{Hg} 4 \mathrm{f}$ state as the $\mathrm{HgTe}$ gets mixed with $\mathrm{ZnO}$. If we assume a rigid shift of the photoemission spectrum, this may suggest an increase of the $\mathrm{V}_{b}-\mathrm{E}_{\mathrm{F}}$ value and reduced $p$-type nature. However, this shift is too small to induce a transition from $p$ to $n$ in $\mathrm{HgTe}$.
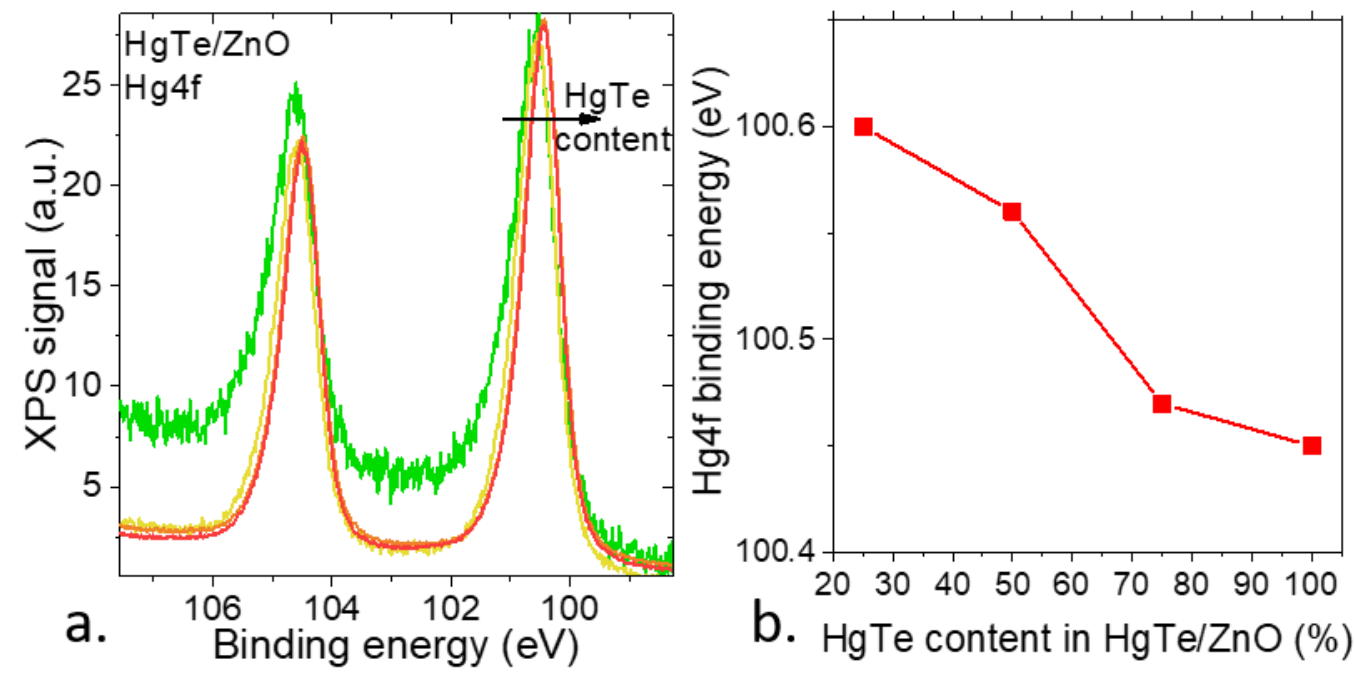

Figure S 21 a. Photoemission spectra relative to the $\mathrm{Hg} 4 \mathrm{f}$ state coming from a thin film made of $\mathrm{HgTe} / \mathrm{ZnO} C \mathrm{CQDs}$ mixture with various $\mathrm{HgTe}$ content. $b$. Energy of the $\mathrm{Hg} 4 f$ state as a function of the HgTe content into an $\mathrm{HgTe} / \mathrm{ZnO} C Q D$ s mixture.

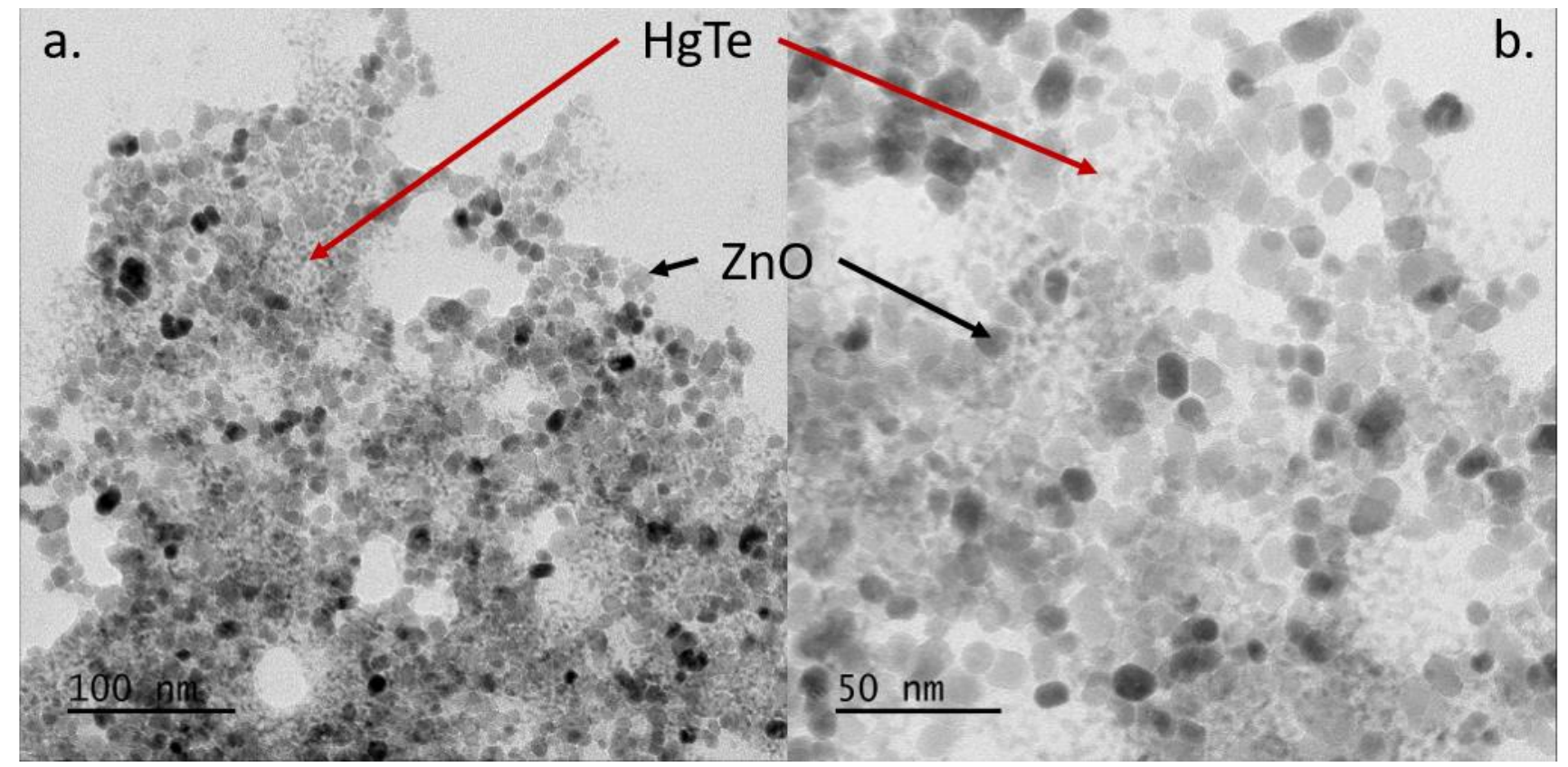

Figure S 22 TEM images of $\mathrm{HgTe}(25 \%) / Z n O$ mixture for two magnifications. 


\section{LED fabrication and characterization}

\subsection{Fabrication}

ITO patterning: We start from commercial glass/ITO substrates of $30 \times 30 \mathrm{~mm}^{2}$ with a low sheet resistance $(7 \Omega / \square)$. Substrates are cut into $15 \times 15 \mathrm{~mm}^{2}$ pieces and cleaned by sonication in an acetone bath during $5 \mathrm{~min}$. The cleaning procedure is followed by rinsing the substrates with acetone and iso-propanol, then dried with a dry $\mathrm{N}_{2}$ flow. Then, 5 -min plasma cleaning is conducted on the surface of ITO. AZ 5214E photoresist is spin-coated for $30 \mathrm{~s}$, then baked at $110{ }^{\circ} \mathrm{C}$ for $90 \mathrm{~s}$. A standard photolithography process is performed using mask aligner for exposing the substrates to UV light for $20 \mathrm{~s}$ through a lithography mask (1 mm width). Photoresist is developed using AZ 726 developer for $20 \mathrm{~s}$ and immediately rinsed with deionized water. After that, exposed ITO surface is completely etched out with $25 \% \mathrm{HCl}$ (in water) for $10 \mathrm{~min}$ at $40{ }^{\circ} \mathrm{C}$, and the substrates are immediately dipped into deionized water. Then, we conduct lift-off process in an acetone bath. The patterned ITO substrates are cleaned with acetone and isopropanol before use.

The ITO substrate has been analyzed using XPS, see Figure $S$ 23. The work function has been determined to be $3.9 \mathrm{eV}$ (Figure $\mathrm{S} 23 \mathrm{~b}$ ), while the value of $\mathrm{Vb}-\mathrm{EF}_{\mathrm{F}}(3.3 \mathrm{eV}$, see Figure $\mathrm{S} 23 \mathrm{c}$ ) is almost as large as the material band gap $(3.4 \mathrm{eV})$, which is consistent with a strong $n$-type doping as expected for transparent conductive layer.
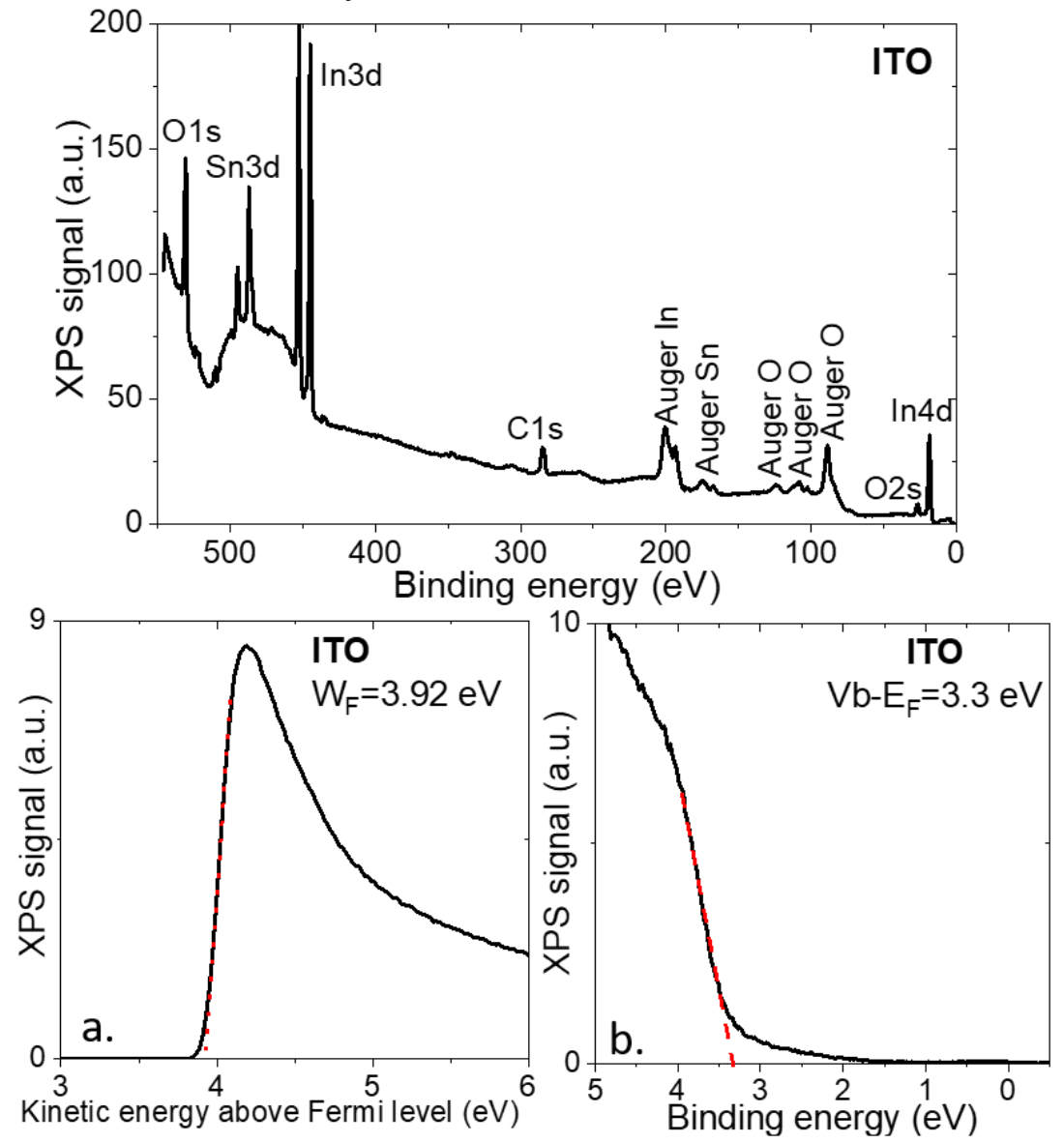

Figure S 23 a. X-ray photoemission overview spectrum relative to the ITO substrate used as transparent conductive layer. $b$. Photoemission spectrum relative to the cut-off of the secondary electrons for the ITO substrate. $c$. Photoemission spectrum relative to the valence band for the ITO substrate. 
$\boldsymbol{n}$-type ZnO layer deposition: On a piece of patterned ITO substrate, a layer of $\mathrm{ZnO}$ was spin coated at a speed of $4000 \mathrm{rpm}$ for $30 \mathrm{~s}$. The film was subsequently annealed at $250{ }^{\circ} \mathrm{C}$ on a heating plate for $5 \mathrm{~min}$. The above steps were repeated one more to obtain a $\mathrm{ZnO}$ film of $100 \mathrm{~nm}$.

Emitting ZnO-HgTe layer deposition: The prepared $\mathrm{HgTe}$ and $\mathrm{ZnO}$ solutions were mixed in separated vials according to the desired volume ratio. The vials were sonicated for a homogeneous mixing. Since the composition of solvent varied with mix ratio, different spin speeds were chosen to make sure that the thickness of 1 -layer deposition is around $40 \mathrm{~nm}$. Taking the $50 \%$ volume ratio of $\mathrm{HgTe}$ and $\mathrm{ZnO}$ as an example, $60 \mathrm{~mL}$ of mixed solution was used to cover the $\mathrm{ZnO}$-coated substrate and spun at $4000 \mathrm{rpm}$ for $30 \mathrm{~s}$. Several drops of MPA in methanol $(0.05 \%)$ were casted on the film and allowed to stay for $10 \mathrm{~s}$ to conduct ligand exchange. The MPA solution was dried by spinning at $4000 \mathrm{rpm}$. The excess ligands were rinsed twice with methanol by drop casting and spin. The speed for pure $\mathrm{HgTe}, 75 \% \mathrm{HgTe}$ and $25 \% \mathrm{HgTe}$ were 2000, 2500 and $6000 \mathrm{rpm}$, respectively. For each device, 2 or 3 emitting layers were deposited.

PbS hole injector: To build a hole injection layer, $\mathrm{PbS}$ nanocrystals absorbing at $960 \mathrm{~nm}$ were used. Inside a glovebox, a PbS solution (30 mg. $\mathrm{mL}^{-1}$ in toluene) was spin coated at $2500 \mathrm{rpm}$ on top of MPA-capped $\mathrm{HgTe} / \mathrm{ZnO}$ emitting layers. EDT in acetonitrile $(0.03 \%)$ was used for the ligand exchange. The EDT in acetonitrile drops was allowed to stay on the film for $1 \mathrm{~min}$ before dried, and rinsed twice with acetonitrile. Three layers of EDT-capped PbS was deposited successively to achieve an overall thickness of $50 \mathrm{~nm}$.

Top contact: After the deposition of PbS nanocrystal layers, the sample was put into a thermal evaporator. $80 \mathrm{~nm}$ of Au was deposited at the vacuum below $5 \times 10^{-6}$ mbar.

The relative band alignment for the different materials involved in the diode can be obtained from Figure S 7, Figure S 10,Figure S 4 and Figure $S 23$ and are summarized in Figure $S 24$. 


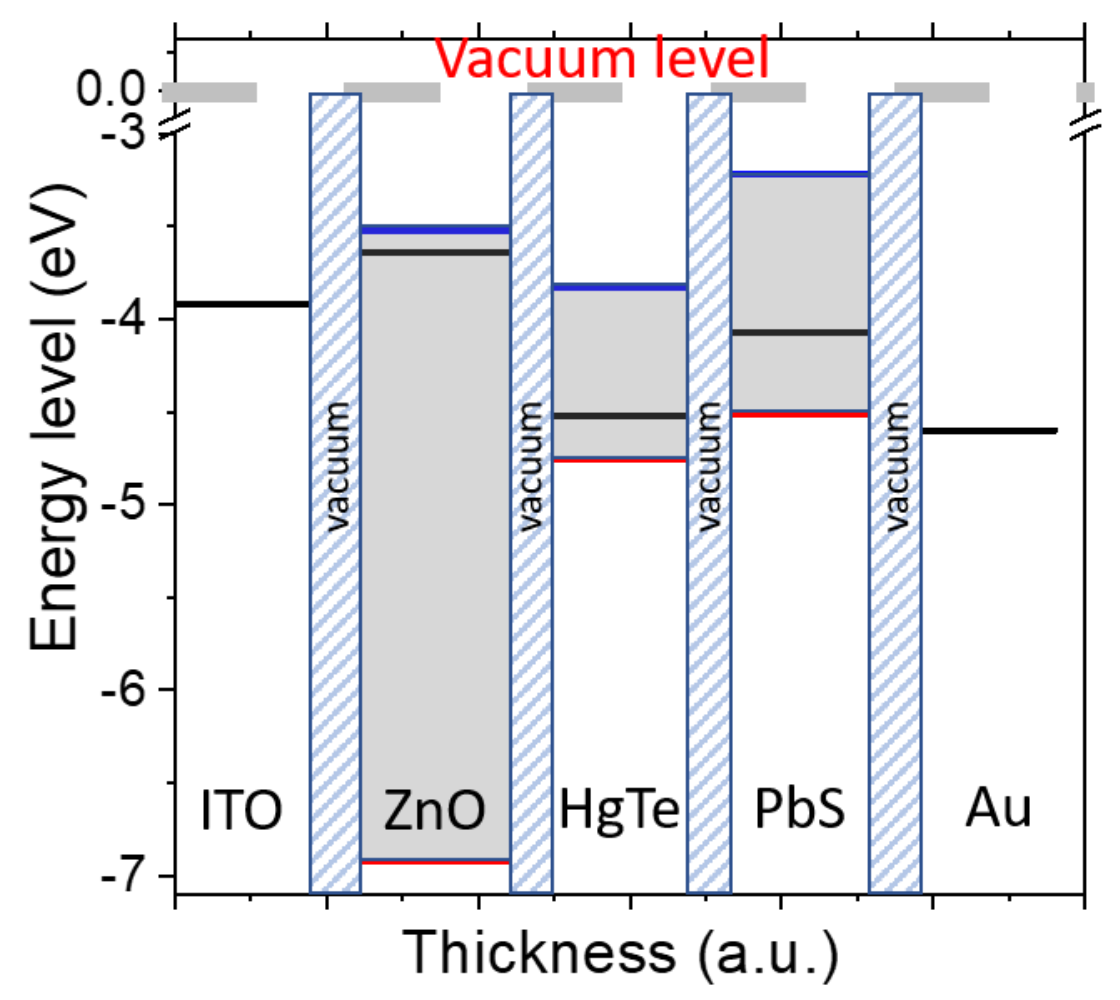

Figure S 24 Band alignment of the different layers involved in the ITO/ZnO/HgTe/PbS/Au diode emitting SWIR light. $0 \mathrm{eV}$ corresponds to the vacuum level, the blue line to the conduction band and the red line to the valence band. 


\subsection{LED characterization}

The device was tested and kept in air atmosphere without encapsulation. Electroluminescence spectrum was collected by a Flame NIR Spectrometer equipped with an InGaAS detector from Ocean optics. EQE and radiance were calculated according to reference. ${ }^{16}$ Considering the Lambertian emission of LED, the flux leaving the device directly can be described as $F_{\text {ext }}=$ $\int_{0}^{\pi / 2} 2 \pi L_{0} \cos \theta \sin \theta d \theta=\pi L_{0}$, with $L_{0}$ the flux per solid angle of light leaving the device in the forward direction. Since the solid angle from the photodetector to the light source is $\Omega=\frac{S_{1}}{l^{2}}$ with $S_{1}$ the area of the detector and $l$ the distance between the light source and detector, then $L_{0}=\frac{P_{d e t}}{\Omega}=$ $\frac{P_{\text {det }} l^{2}}{s_{1}}$ and $F_{\text {ext }}=\frac{\pi P_{\text {det }} l^{2}}{s_{1}}$. The number of photons emitted per second to the forward direction then can be calculated by $N_{P}=\frac{F_{e x t}}{h v}=\frac{\pi P_{\text {det }} l^{2} \lambda}{s_{1} h c}$, with $\lambda$ the wavelength of electroluminescence, $h$ the Plank's constant and $c$ the speed of light. The number of electrons injected per second can be obtained by $N_{e}=\frac{I}{e}$, with $I$ the current flow of the device. Thus, the EQE can be calculated as $E=$ $\frac{N_{p}}{N_{e}}=\frac{\pi P_{\mathrm{det}} l^{2} \lambda e}{s_{1} h c l}$. The irradiance of the device is $R=\frac{F_{e x t}}{\pi s_{2}}=\frac{\pi P_{\mathrm{det}} l^{2}}{\pi s_{1} s_{2}}$, with $S_{2}$ the area of the pixel. During the measurement, we collected current-voltage-power characteristics with a Keithley K2634B source meter unit and a PM100A power meter coupled with the S122C Ge detector from Thorlabs.

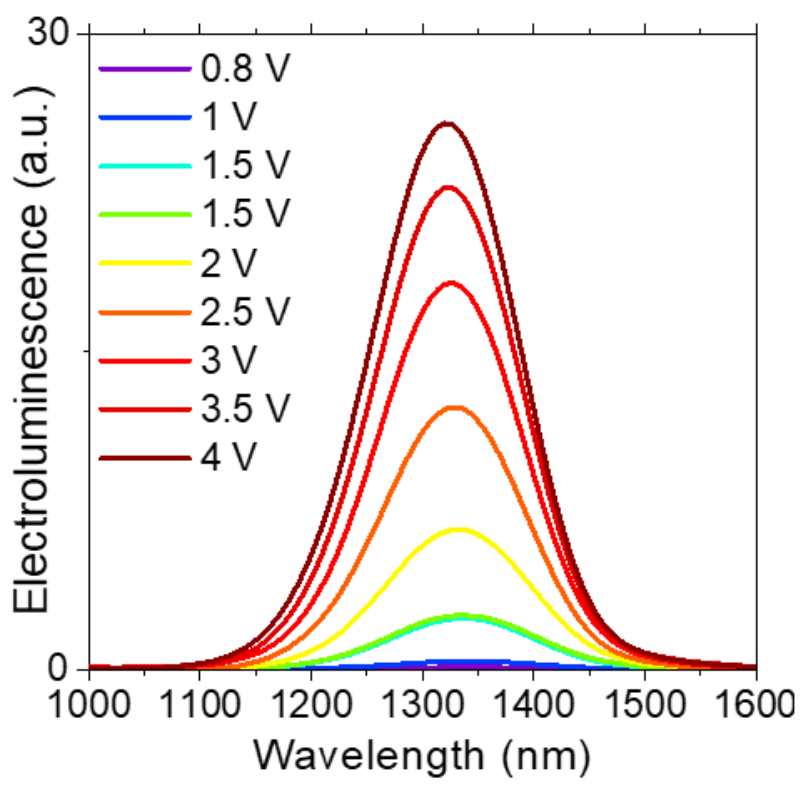

Figure S 25 Electroluminescence spectra of the diode made of ITO/ZnO/HgTe/PbS/Au emitting at $1320 \mathrm{~nm}$ operated under different biases. 
Figure S 26 and Table S 2 discuss the impact of the HgTe content in the emissive layer

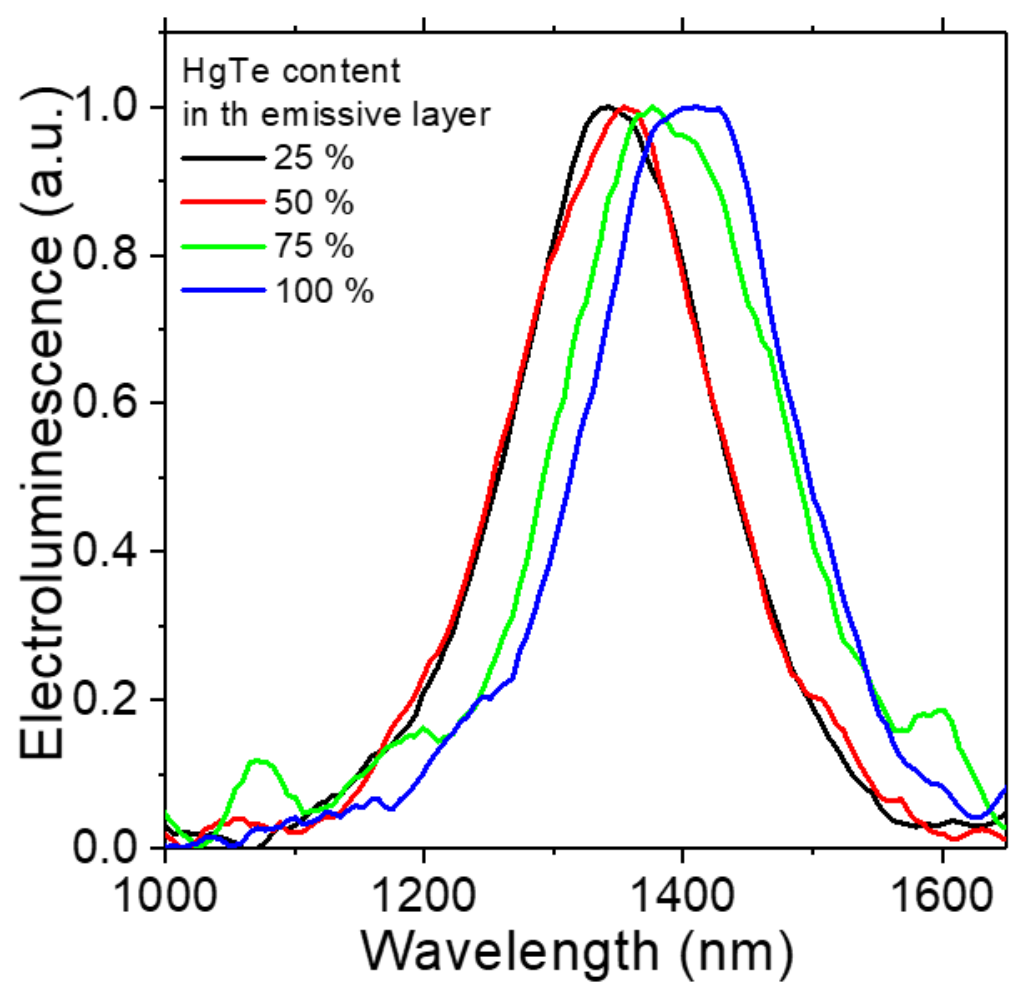

Figure S 26 Electroluminescence spectra of the diode made of ITO/ZnO/HgTe/PbS/Au with various $\mathrm{HgTe}$ contents in the emissive layer

Table S 2 Performances of diode made of ITO/ZnO/HgTe/PbS/Au with various $\mathrm{HgTe}$ contents in the emissive layer

\begin{tabular}{llll}
\hline & $\begin{array}{l}\text { Emitting } \\
\text { layer }\end{array}$ & $\begin{array}{l}\text { EL } \\
\text { peak } \\
\text { (nm) }\end{array}$ & $\begin{array}{l}\text { EQE max } \\
(\%)\end{array}$ \\
\hline S1 & $\begin{array}{l}100 \% \\
\text { HgTe }\end{array}$ & 1410 & 0.04 \\
\hline S2 & $\begin{array}{l}75 \% \\
\text { HgTe }\end{array}$ & 1390 & 0.16 \\
\hline S3 & $\begin{array}{l}50 \% \\
\mathrm{HgTe}\end{array}$ & 1360 & 0.75 \\
\hline S4 & $\begin{array}{l}25 \% \\
\mathrm{HgTe}\end{array}$ & 1350 & 1.1 \\
\hline
\end{tabular}




\subsection{Comparison with state-of-the-art LEDs}

In Table S 3, we have listed some results relative to light emitting device based on CQDs and operating in the near IR and SWIR range of wavelength. Most of the results are based on PbS CQDs. In this case different geometries including vertical geometry and light emitting field effect transistor have been tested. Alternative to $\mathrm{PbS}$ are $\mathrm{Ag}_{2} \mathrm{~S},{ }^{17} \mathrm{PbSe},{ }^{18}$ and InAs. ${ }^{19}$ Only few reports focus on electroluminescence from HgTe CQDs. ${ }^{20,21}$

Table S 3 : Figure of merit for NIR and SWIR nanocrystal-based LED

\begin{tabular}{|c|c|c|c|c|c|c|c|c|c|}
\hline S.N. & Device structure & $\begin{array}{l}\text { Active } \\
\text { material }\end{array}$ & $\begin{array}{l}\text { PLQ } \\
Y \\
(\%)\end{array}$ & $\begin{array}{l}\text { EL } \\
\text { pea } \\
k \\
(n m)\end{array}$ & $\begin{array}{l}\text { Turn } \\
\text { on } \\
\text { Voltag } \\
\text { e } \\
\text { (V) }\end{array}$ & $\begin{array}{l}\text { Radianc } \\
\text { e } \\
\text { (W/sr.m } \\
{ }^{2} \text { ) }\end{array}$ & $\begin{array}{l}\text { EQE } \\
(\%)\end{array}$ & $\begin{array}{l}\text { Life } \\
\text { tim } \\
\text { e }\end{array}$ & $\begin{array}{l}\text { Refer } \\
\text { ence }\end{array}$ \\
\hline 1 & $\begin{array}{l}\text { Vertical } \\
\left(\mathrm{ITO} / \mathrm{TiO}_{2} / \text { perovskite+ }\right. \\
\mathrm{Ag}_{2} \mathrm{~S}_{2} @ \mathrm{SiO}_{2} / \text { porphyrin } \\
/ \\
\mathrm{MoO}_{3} / \mathrm{Ag}\end{array}$ & $\begin{array}{l}\text { Perovskite } \\
+\mathrm{Ag}_{2} \mathrm{~S} @ \mathrm{SiO} \\
2\end{array}$ & 84 & $\begin{array}{l}139 \\
7\end{array}$ & 2 & 83.93 & 16.98 & $\begin{array}{l}20 \\
\text { days }\end{array}$ & 17 \\
\hline 2 & $\begin{array}{l}\text { Vertical } \\
\text { (ITO/ZnO/PbS:ZnO/P } \\
\text { bS/ } \\
\mathrm{Au})\end{array}$ & $\mathrm{PbS}: \mathrm{ZnO}$ & 75 & $\begin{array}{l}140 \\
0\end{array}$ & 0.6 & 9.0 & 7.9 & $48 \mathrm{~h}$ & 10 \\
\hline 3 & FET & $\mathrm{PbS}$ & $<1$ & $\begin{array}{l}148 \\
0\end{array}$ & & - & $\begin{array}{l}1.3 \times 1 \\
0^{-5}\end{array}$ & - & 22 \\
\hline 4 & $\begin{array}{l}\text { Vertical } \\
\text { (ITO/ZnO/QDs/NPB/ } \\
\left.\mathrm{MoO}_{3} / \mathrm{Al}\right)\end{array}$ & $\begin{array}{l}\mathrm{PbS} / \mathrm{CdS} \\
\text { core/shell }\end{array}$ & 52 & $\begin{array}{l}150 \\
0\end{array}$ & & 6.04 & 4.12 & - & 23 \\
\hline 5 & $\begin{array}{l}\text { Vertical } \\
\left(\mathrm{ITO} / \mathrm{TiO}_{2} / \mathrm{QDs} / \mathrm{F} 8 / \mathrm{Mo}\right. \\
\left.\mathrm{O}_{3} / \mathrm{Al}\right)\end{array}$ & $\begin{array}{l}\mathrm{PbS}+ \\
\text { perovskite }\end{array}$ & - & $\begin{array}{l}1160 \\
- \\
1390\end{array}$ & $<1$ & 2.6 & 5.2 & - & 16 \\
\hline 6 & $\begin{array}{l}\text { Vertical } \\
\text { (ITO/PbS/Ag) }\end{array}$ & $\mathrm{PbS}$ & - & $\begin{array}{l}135 \\
0\end{array}$ & 1.2 & 0.29 & 1.6 & - & 24 \\
\hline 7 & $\begin{array}{l}\text { Vertical } \\
(\mathrm{ITO} / \mathrm{ZnO} / \mathrm{QDs} / \mathrm{CPB} / \\
\left.\mathrm{MoO}_{3} / \mathrm{Au}\right)\end{array}$ & $\begin{array}{l}\mathrm{PbS} / \mathrm{CdS} \\
\text { core/shell }\end{array}$ & 33 & $\begin{array}{l}120 \\
0\end{array}$ & 0.6 & 0.75 & 4.3 & - & 25 \\
\hline 8 & $\begin{array}{l}\text { Vertical } \\
\text { (ITO/PEDOT:PSS/QD } \\
\text { s/ } \\
\text { ZnO/Al) }\end{array}$ & $\mathrm{PbS}$ & - & $\begin{array}{l}105 \\
4\end{array}$ & 0.7 & 6.4 & 2 & - & 26 \\
\hline 9 & Vertical & $\begin{array}{l}\text { PbSe: } \\
\text { MEH-PVV }\end{array}$ & - & $\begin{array}{l}128 \\
0\end{array}$ & 3 & - & 0.83 & - & 18 \\
\hline
\end{tabular}




\begin{tabular}{|c|c|c|c|c|c|c|c|c|c|}
\hline & $\begin{array}{l}\text { (ITO/PEDOT:PSS/QD } \\
\text { s/BCP/LiF/AI) }\end{array}$ & & & & & & & & \\
\hline 10 & $\begin{array}{l}\text { Vertical } \\
\text { (ITO/Pentacene/QDs/ } \\
\text { BCP/AI) }\end{array}$ & $\mathrm{PbS}$ & & $\begin{array}{l}120 \\
0\end{array}$ & 1 & - & 1.15 & - & 27 \\
\hline 11 & $\begin{array}{l}\text { Vertical } \\
\text { (ITO/PVV/QDs/Mg/Ag } \\
\text { ) }\end{array}$ & $\begin{array}{l}\text { PbS:MEH- } \\
\text { PVV }\end{array}$ & 2.2 & $\begin{array}{l}116 \\
0\end{array}$ & - & - & 0.27 & - & 28 \\
\hline 14 & $\begin{array}{ll}\text { Vertical } & \\
\text { ITO/TPD } & \text { or } \\
\text { NPD/QDs/Alq } & \text { or } \\
\text { BCP/Mg:Ag } & \end{array}$ & $\mathrm{PbSe}$ & 1.5 & $\begin{array}{l}133 \\
0- \\
156 \\
0\end{array}$ & - & - & $\begin{array}{l}0.000 \\
1\end{array}$ & - & 29 \\
\hline 15 & $\begin{array}{l}\text { Vertical } \\
\text { ITO/PEDOT:PSS/QD } \\
\text { s/Ca/Al }\end{array}$ & $\begin{array}{l}\text { InAs/ZnSe } \\
\text { Core/shell }\end{array}$ & - & $\begin{array}{l}100 \\
0- \\
130 \\
0\end{array}$ & 2 & - & 0.5 & - & 19 \\
\hline 12 & $\begin{array}{l}\text { Vertical } \\
\text { (ITO/PEDOT/HgTe/AI } \\
\text { ) }\end{array}$ & $\mathrm{HgTe}$ & - & $\begin{array}{l}160 \\
0\end{array}$ & 1 & - & 0.02 & - & 21 \\
\hline 13 & $\begin{array}{l}\text { Vertical } \\
\text { ITO/QDs/AI }\end{array}$ & $\begin{array}{l}\text { HgTe:MeLP } \\
\text { PP }\end{array}$ & - & $\begin{array}{l}130 \\
0\end{array}$ & 10 & - & - & - & 20 \\
\hline $\begin{array}{l}\text { This } \\
\text { wor } \\
k\end{array}$ & $\begin{array}{l}\text { Vertical } \\
\text { (ITO/ZnO/HgTe:ZnO/ } \\
\mathrm{PbS} / \\
\mathrm{Au})\end{array}$ & $\mathrm{HgTe}$ & & $\begin{array}{l}125 \\
0- \\
160 \\
0\end{array}$ & 0.6 & 9 & 0.67 & $30 \mathrm{~h}$ & \\
\hline
\end{tabular}




\subsection{Active imaging}

For active imaging, the HgTe LED is driven with a constant bias (2-2.5 $\mathrm{V}$ corresponding to current in the 20-30 mA though the diode). Imaging is obtained from an InGaAs camera (Widy Sens from NIT). Even though the integration time is high, in the order of tens of ms, we can image the LED and the scattered light without saturation thanks to the use of the logarithmic mode.

In Figure S 27, we use SWIR active imaging to distinguish two solutions which looks brown in the visible a solution of coffee (mostly made of water) and a solution of PbS NCs in toluene. In the SWIR the coffee appears dark due to the high absorption of water, while PbS nanocrystals which are photoluminescent appear bright while excited with a blue laser.

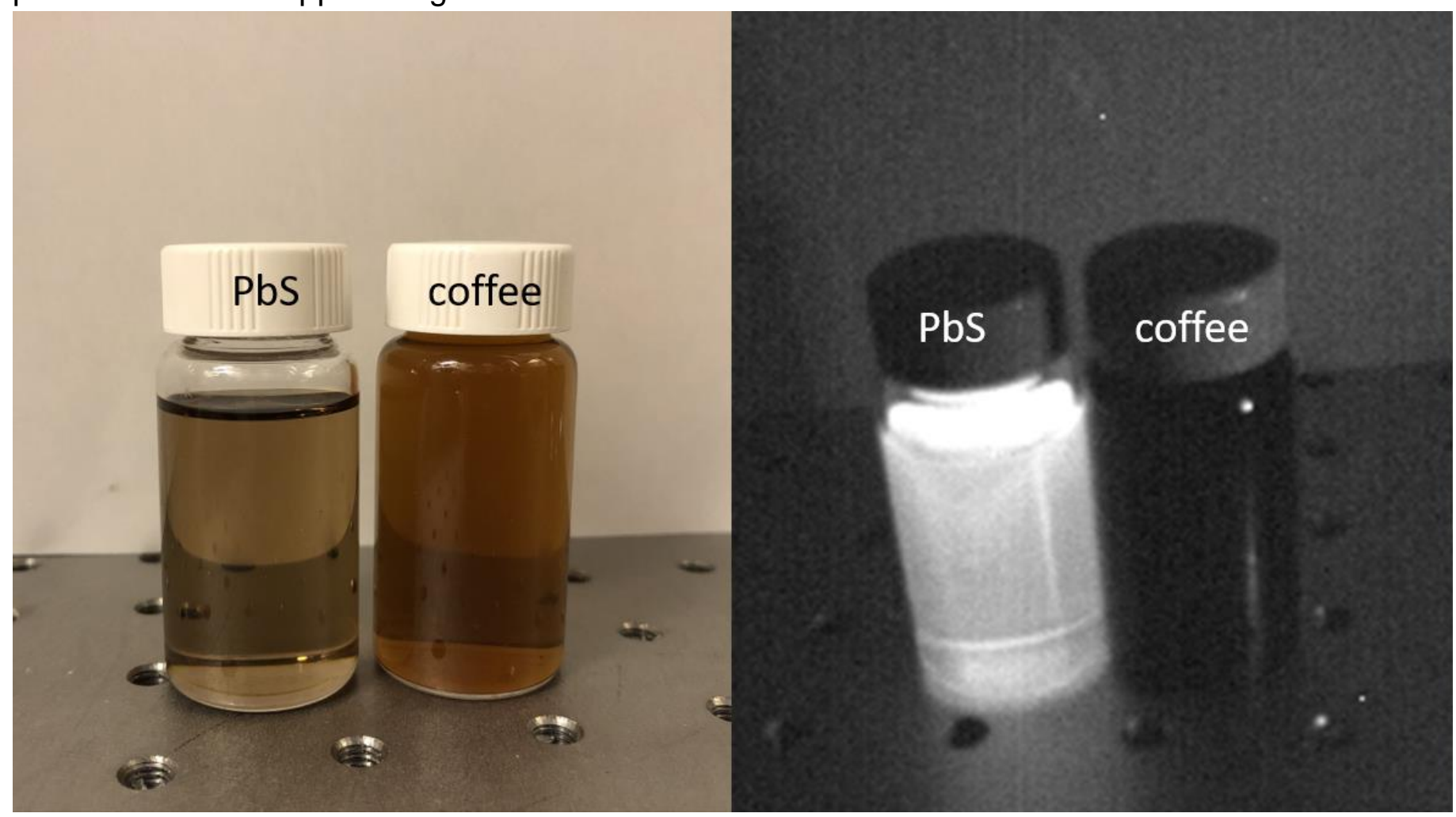

Figure S 27 Visible (a.) and SWIR (b) images of two vials containing a brown mixture, one is PbS $C Q D$ in toluene. The other one is coffee. The scene is illuminated with the HgTe LED and a blue laser diode to excite the PbS CQD. Imaging is obtained form a InGaAs focal plane array. 


\section{REFERENCES}

(1) Geiregat, P.; Houtepen, A. J.; Sagar, L. K.; Infante, I.; Zapata, F.; Grigel, V.; Allan, G.; Delerue, C.; Van Thourhout, D.; Hens, Z. Continuous-Wave Infrared Optical Gain and Amplified Spontaneous Emission at Ultralow Threshold by Colloidal HgTe Quantum Dots. Nat. Mater. 2018, 17, 35-42.

(2) Lhuillier, E.; Keuleyan, S.; Guyot-Sionnest, P. Optical Properties of HgTe Colloidal Quantum Dots. Nanotechnology 2012, 23, 175705.

(3) Jagtap, A.; Martinez, B.; Goubet, N.; Chu, A.; Livache, C.; Gréboval, C.; Ramade, J.; Amelot, D.; Trousset, P.; Triboulin, A.; et al. Design of a Unipolar Barrier for a Nanocrystal-Based Short-Wave Infrared Photodiode. ACS Photonics 2018, 5, 4569-4576.

(4) Chu, A.; Martinez, B.; Ferré, S.; Noguier, V.; Gréboval, C.; Livache, C.; Qu, J.; Prado, Y.; Casaretto, N.; Goubet, N.; et al. HgTe Nanocrystals for SWIR Detection and Their Integration up to the Focal Plane Array. ACS Appl. Mater. Interfaces 2019, 11, 33116-33123.

(5) Goubet, N.; Jagtap, A.; Livache, C.; Martinez, B.; Portalès, H.; Xu, X. Z.; Lobo, R. P. S. M.; Dubertret, B.; Lhuillier, E. Terahertz HgTe Nanocrystals: Beyond Confinement. J. Am. Chem. Soc. 2018, 140, 5033-5036.

(6) Goubet, N.; Thomas, M.; Gréboval, C.; Chu, A.; Qu, J.; Rastogi, P.; Chee, S.-S.; Goyal, M.; Zhang, Y.; Xu, X. Z.; et al. Near- to Long-Wave-Infrared Mercury Chalcogenide Nanocrystals from Liquid Mercury. J. Phys. Chem. C 2020, 124, 8423-8430.

(7) Livache, C.; Izquierdo, E.; Martinez, B.; Dufour, M.; Pierucci, D.; Keuleyan, S.; Cruguel, H.; Becerra, L.; Fave, J. L.; Aubin, H.; et al. Charge Dynamics and Optolectronic Properties in HgTe Colloidal Quantum Wells. Nano Lett. 2017, 17, 4067-4074.

(8) Martinez, B.; Livache, C.; Notemgnou Mouafo, L. D.; Goubet, N.; Keuleyan, S.; Cruguel, H.; Ithurria, S.; Aubin, H.; Ouerghi, A.; Doudin, B.; et al. HgSe Self-Doped Nanocrystals as a Platform to Investigate the Effects of Vanishing Confinement. ACS Appl. Mater. Interfaces 2017, 9, 36173-36180.

(9) Martinez, B.; Livache, C.; Goubet, N.; Jagtap, A.; Cruguel, H.; Ouerghi, A.; Lacaze, E.; Silly, M. G.; Lhuillier, E. Probing Charge Carrier Dynamics to Unveil the Role of Surface Ligands in HgTe Narrow Band Gap Nanocrystals. J. Phys. Chem. C 2018, 122, 859-865.

(10) Pradhan, S.; Di Stasio, F.; Bi, Y.; Gupta, S.; Christodoulou, S.; Stavrinadis, A.; Konstantatos, G. High-Efficiency Colloidal Quantum Dot Infrared Light-Emitting Diodes via Engineering at the Supra-Nanocrystalline Level. Nat. Nanotechnol. 2019, 14, 72-79.

(11) Hines, M. A.; Scholes, G. D. Colloidal PbS Nanocrystals with Size-Tunable Near-Infrared Emission: Observation of Post-Synthesis Self-Narrowing of the Particle Size Distribution. Adv. Mater. 2003, 15, 1844-1849.

(12) Ramade, J.; Qu, J.; Chu, A.; Gréboval, C.; Livache, C.; Goubet, N.; Martinez, B.; Vincent, G.; Lhuillier, E. Potential of Colloidal Quantum Dot Based Solar Cells for Near-Infrared Active Detection. ACS Photonics 2020, 7, 272-278.

(13) Brown, P. R.; Kim, D.; Lunt, R. R.; Zhao, N.; Bawendi, M. G.; Grossman, J. C.; Bulović, V. Energy Level Modification in Lead Sulfide Quantum Dot Thin Films through Ligand Exchange. ACS Nano 2014, 8, 5863-5872.

(14) Melnychuk, C.; Guyot-Sionnest, P. Slow Auger Relaxation in HgTe Colloidal Quantum Dots. J. Phys. Chem. Lett. 2018, 9, 2208-2211.

(15) Bergeard, N.; Silly, M. G.; Krizmancic, D.; Chauvet, C.; Guzzo, M.; Ricaud, J. P.; Izquierdo, M.; Stebel, L.; Pittana, P.; Sergo, R.; et al. Time-Resolved Photoelectron Spectroscopy Using Synchrotron Radiation Time Structure. J Synchrotron Rad 2011, 18, 245-250.

(16) Gong, X.; Yang, Z.; Walters, G.; Comin, R.; Ning, Z.; Beauregard, E.; Adinolfi, V.; Voznyy, O.; Sargent, E. H. Highly Efficient Quantum Dot Near-Infrared Light-Emitting Diodes. Nature Photonics 2016, 10, 253-257.

(17) Vasilopoulou, M.; Kim, H. P.; Kim, B. S.; Papadakis, M.; Ximim Gavim, A. E.; Macedo, A. G.; Jose da Silva, W.; Schneider, F. K.; Mat Teridi, M. A.; Coutsolelos, A. G.; et al. Efficient 
Colloidal Quantum Dot Light-Emitting Diodes Operating in the Second near-Infrared Biological Window. Nat. Photonics 2020, 14, 50-56.

(18) Choudhury, K. R.; Song, D. W.; So, F. Efficient Solution-Processed Hybrid PolymerNanocrystal near Infrared Light-Emitting Devices. Organic Electronics 2010, 11, 23-28.

(19) Tessler, N.; Medvedev, V.; Kazes, M.; Kan, S.; Banin, U. Efficient Near-Infrared Polymer Nanocrystal Light-Emitting Diodes. Science 2002, 295, 1506-1508.

(20) Koktysh, D. S.; Gaponik, N.; Reufer, M.; Crewett, J.; Scherf, U.; Eychmüller, A.; Lupton, J. M.; Rogach, A. L.; Feldmann, J. Near-Infrared Electroluminescence from HgTe Nanocrystals. Chem. Phys. Chem. 2004, 5, 1435-1438.

(21) O'Connor, É.; O'Riordan, A.; Doyle, H.; Moynihan, S.; Cuddihy, A.; Redmond, G. NearInfrared Electroluminescent Devices Based on Colloidal HgTe Quantum Dot Arrays. Appl. Phys. Lett. 2005, 86, 201114.

(22) Shulga, A. G.; Kahmann, S.; Dirin, D. N.; Graf, A.; Zaumseil, J.; Kovalenko, M. V.; Loi, M. A. Electroluminescence Generation in PbS Quantum Dot Light-Emitting Field-Effect Transistors with Solid-State Gating. ACS Nano 2018, 12, 12805-12813.

(23) Yang, X.; Ren, F.; Wang, Y.; Ding, T.; Sun, H.; Ma, D.; Sun, X. W. lodide Capped PbS/CdS Core-Shell Quantum Dots for Efficient Long-Wavelength near-Infrared Light-Emitting Diodes. Sci. Rep. 2017, 7, 14741.

(24) Yang, Z.; Voznyy, O.; Liu, M.; Yuan, M.; Ip, A. H.; Ahmed, O. S.; Levina, L.; Kinge, S.; Hoogland, S.; Sargent, E. H. All-Quantum-Dot Infrared Light-Emitting Diodes. ACS Nano 2015, 9, 12327-12333.

(25) Supran, G. J.; Song, K. W.; Hwang, G. W.; Correa, R. E.; Scherer, J.; Dauler, E. A.; Shirasaki, Y.; Bawendi, M. G.; Bulović, V. High-Performance Shortwave-Infrared Light-Emitting Devices Using Core-Shell (PbS-CdS) Colloidal Quantum Dots. Adv. Mater. 2015, 27, 1437-1442.

(26) Sun, L.; Choi, J. J.; Stachnik, D.; Bartnik, A. C.; Hyun, B.-R.; Malliaras, G. G.; Hanrath, T.; Wise, F. W. Bright Infrared Quantum-Dot Light-Emitting Diodes through Inter-Dot Spacing Control. Nature Nanotechnol. 2012, 7, 369-373.

(27) Bourdakos, K. N.; Dissanayake, D. M. N. M.; Lutz, T.; Silva, S. R. P.; Curry, R. J. Highly Efficient Near-Infrared Hybrid Organic-Inorganic Nanocrystal Electroluminescence Device. Appl. Phys. Lett. 2008, 92, 153311.

(28) Konstantatos, G.; Huang, C.; Levina, L.; Lu, Z.; Sargent, E. H. Efficient Infrared Electroluminescent Devices Using Solution-Processed Colloidal Quantum Dots. Advanced Functional Materials 2005, 15, 1865-1869.

(29) Steckel, J. S.; Coe-Sullivan, S.; Bulović, V.; Bawendi, M. G. $1.3 \mu \mathrm{m}$ to $1.55 \mu \mathrm{m}$ Tunable Electroluminescence from PbSe Quantum Dots Embedded within an Organic Device. Adv. Mater. 2003, 15, 1862-1866. 